$41(1) \mid 2012$

Varia

\title{
El establecimiento de relaciones de poder a través del uso del espacio residencial en la provincia Wari de Moquegua
}

L'utilisation de l'espace résidential pour l'établissement des relations de pouvoir dans la province wari de Moquegua

The use of residential space in establishing power relations in the Wari province of Moquegua

Donna J. Nash

(2) OpenEdition

Journals

Edición electrónica

URL: http://journals.openedition.org/bifea/1003

DOI: $10.4000 /$ bifea. 1003

ISSN: 2076-5827

Editor

Institut Français d'Études Andines

Edición impresa

Fecha de publicación: 1 enero 2012

Paginación: 1-34

ISSN: 0303-7495

Referencia electrónica

Donna J. Nash, «El establecimiento de relaciones de poder a través del uso del espacio residencial en la provincia Wari de Moquegua », Bulletin de l'Institut français d'études andines [En línea], 41 (1) | 2012,

Publicado el 01 agosto 2012, consultado el 10 diciembre 2020. URL : http://journals.openedition.org/ bifea/1003 ; DOl : https://doi.org/10.4000/bifea.1003

\section{c) (i) $(9$}

Les contenus du Bulletin de l'Institut français d'études andines sont mis à disposition selon les termes de la licence Creative Commons Attribution - Pas d'Utilisation Commerciale - Pas de Modification 4.0 International. 


\title{
El establecimiento de relaciones de poder a través del uso del espacio residencial en la provincia Wari de Moquegua
}

\author{
Donna J. Nash*
}

\begin{abstract}
Resumen
El imperio wari fue un Estado expansivo que incorporó a diversos grupos de los Andes peruanos desde 600 d. C. hasta 1000 d. C. En general, la elite estatal wari estableció relaciones asimétricas con algunas organizaciones políticas regionales, pero en algunos casos reemplazó a los líderes locales por funcionarios estatales. Por otro lado, este poderoso imperio construyó centros provinciales que fueron lugares donde los funcionarios del Estado interactuaban con los líderes regionales. En ocasiones, estos líderes regionales mantuvieron sus mismos roles y continuaron gobernando a sus súbditos a través de interacciones sociopolíticas mientras estaban siendo asumidos por la economía política del nuevo aparato estatal. Así, en algunas provincias se construyeron edificios monumentales formales que fueron importantes para la formación de la estructura política del imperio wari. Estos edificios han sido interpretados como centros administrativos, pero se hace notar que importantes relaciones sociopolíticas dirigidas a mantener el poder y el control estatal sobre las regiones no estuvieron limitadas a estos centros monumentales. Varios investigadores han sugerido que si Wari fue un Estado expansivo, este debió tener importantes relaciones sociopolíticas entre los trabajadores (mano de obra) y los administradores estatales, en varios niveles y bajo una compleja jerarquía. En este trabajo se sugiere que el uso de los espacios de las residencias de elite del sitio wari de Cerro Mejía, estuvo diseñado para llevar a cabo importantes actividades políticas. Este sitio presenta espacios donde se llevaron a cabo reuniones y/o celebraciones, u otro tipo de actividades, que fueron importantes para establecer y mantener el control de pequeños grupos regionales incorporados a la esfera política wari. Las excavaciones llevadas a cabo en Cerro Mejía y las comparaciones hechas con las residencias de elite de Cerro Baúl, ambos sitios localizados en Moquegua, proveen un ejemplo claro de la manera como los espacios domésticos fueron utilizados y diseñados para facilitar las relaciones de poder asimétricas de este temprano Estado andino.
\end{abstract}

Palabras clave: relaciones de poder, arqueología de hogares, uso del espacio, festines, imperios, Wari, Moquegua

* Department of Anthropology, University of North Carolina Greensboro (Greensboro, NC 274026170, EE. UU.). E-mail: djnash@uncg.edu 


\title{
L'utilisation de l'espace résidential pour l'établissement des relations de pouvoir dans la province wari de Moquegua
}

\section{Résumé}

Lors de son expansion dans les Andes péruviennes entre 600 et 1000 apr. J.-C., I'empire Wari a intégré de nombreux groupes ethniques. Les gouvernants wari ont établi des relations assymétriques avec plusieurs entités régionales ou, dans certains cas, ont mis des fonctionnaires à leur tête. Dans les centres provinciaux de ce puissant empire, ces derniers ont collaboré avec les chefs locaux. Ceux-ci, en de nombreuses circonstances, ont fait de même et ont continué de gouverner leurs sujets alors qu'ils étaient partie prenante de l'économie politique du nouvel appareil d'État. Des édifices monumentaux furent construits dans les provinces et ont été interprétés par la suite comme des centres administratifs. Cependant, les relations socio-politiques essentielles au maintien du pouvoir et au contrôle des régions ne se limitaient pas à ces centres monumentaux. Si Wari était effectivement un État conquérant, il a bien dû régenter les relations entre la main d'oeuvre et les fonctionnaires qui les dirigeaient, suivant une hiérarchie complexe. Dans ce travail, il est suggéré que l'usage de l'espace domestique par l'élite du site wari de Cerro Mejía, a été conçu pour permettre l'exercice d'activités politiques d'importance, tels que des assemblées, des banquets et autres activités autorisant le contrôle des petits groupes régionaux intégrés à la sphère politique wari. Les fouilles conduites à Cerro Mejía et les comparaisons établies avec les domiciles de l'élite mis à jour à Cerro Baúl — les deux sites étant situés à Moquegua—, livrent un bon exemple de l'usage des espaces domestiques dans le cadre des relations de pouvoir assymétriques propres aux débuts de cet état andin.

Mots clés : relations de pouvoir, l'archéologie de la maison, l'utilisation de l'space, festines, empires, Wari, Moquegua

\section{The use of residential space in establishing power relations in the Wari province of Moquegua}

\begin{abstract}
The Wari Empire was an expansive state that incorporated many groups in the Peruvian Andes ca. AD600-1000. The ruling members of Wari society established asymmetrical relations with many regional polities or replaced them with state officials. In the provincial centers of this powerful empire, state officials interacted with regional leaders. Regional leaders, in many instances, did the same and continued to manage their followers through socio-political interactions as they were subsumed in the Wari political economy. Formal monumental settings for important socio-political relations underpinning the centralization of the Wari state were built in a few provincial areas, and have been interpreted as administrative centers, however socio-political relations crucial to maintaining power and control over many regions were not limited to these monumental centers. Socio-political connections between laborers and administrators would have been important at a number of scales and a complex hierarchy should be present if Wari is a state as many archaeologists suggest. This paper describes the use of space in elite residences at the Wari site of Cerro Mejia and demonstrate that these residential settings were organized around important political activities, such as holding meetings and hosting feasts, and other activities that would have played an important role in establishing and maintaining control of small regional groups incorporated into the Wari political sphere. Excavations on Cerro Mejia and comparisons with elite residences on Cerro Baúl, both located in Moquegua, provide a good example of how houses were used and designed to facilitate asymmetrical power relations in the early Andean Wari Empire.
\end{abstract}

Key words: power relations, household archelogy, use of space, feasting, empires, Wari, Moquegua 
Los wari establecieron una colonia en la parte más alta y árida de la cuenca del río Moquegua alrededor del año 600 d. C. (Williams, 2001) (fig. 1). Sin embargo, la gente que habitaba esta colonia no era originaria de Moquegua, sino que se trataba de colonos foráneos (Moseley et al., 1991). La evidencia más notable de esta intrusión imperial no es la arquitectura ya que las construcciones mismas no son prueba de ello, pero sí lo es la organización del espacio que las hace indudablemente wari. Estos espacios no solo tuvieron fines estéticos, sino que al parecer fueron parte integral de las relaciones de poder y del gobierno wari (Nash \& Williams, 2005).

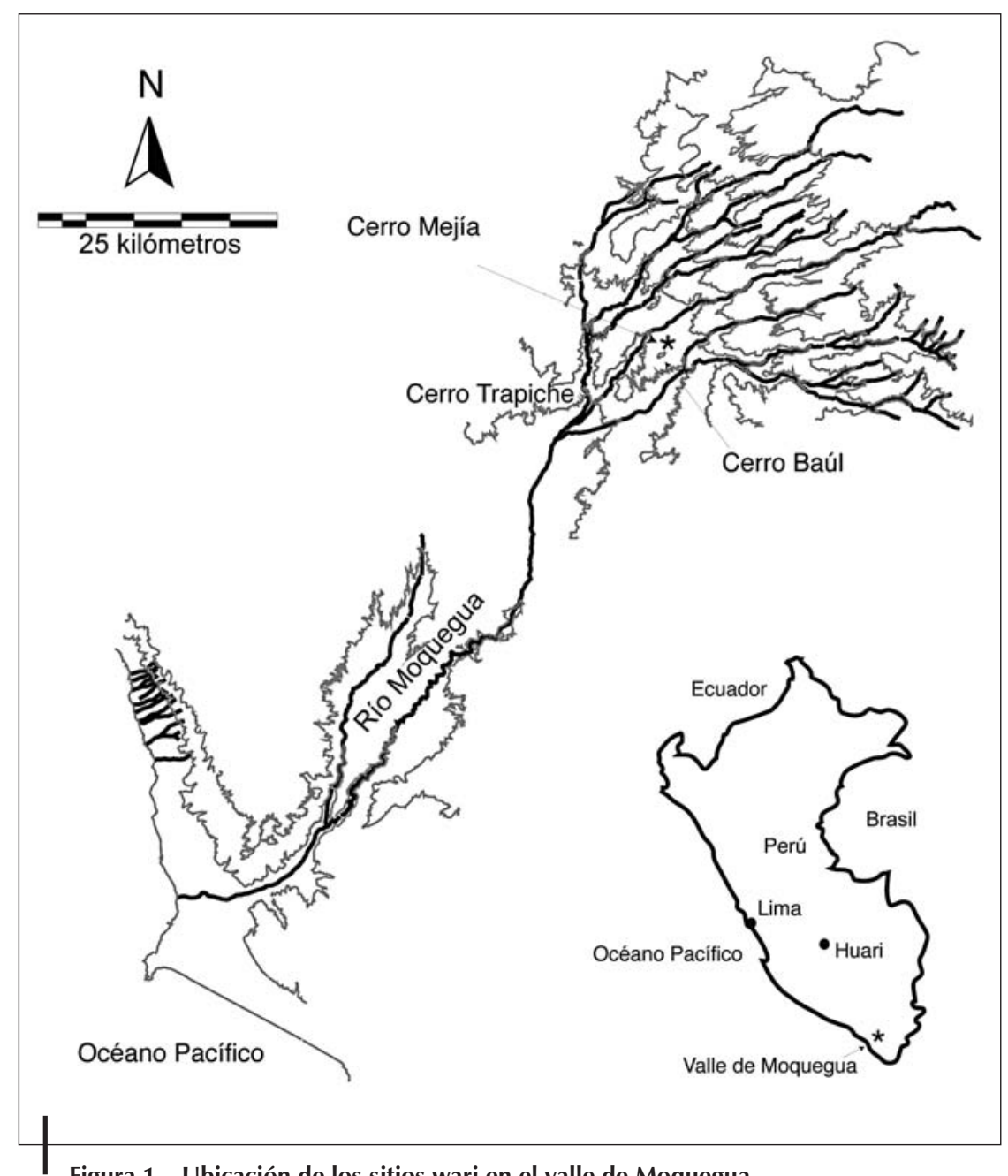

Figura 1 - Ubicación de los sitios wari en el valle de Moquegua 
La distancia de la capital wari, la extraordinaria naturaleza del centro provincial construido en la cima de Cerro Baúl y su infraestructura de servicio, demuestran la magnitud de labor empleada y administrada (Moseley et al., 2005). Esta colonia no pudo haberse instalado en la zona sin la tutela y patrocinio del Estado wari. Esto debido a que la estimación de la población es insuficiente para invertir en la fuerza de trabajo necesitada para construir el sistema colonial de terrazas agrícolas y canales, así como la arquitectura monumental de Cerro Baúl, entre otros tipos de asentamientos. Dejando a un lado la motivación de la colonización wari en esta región, surge la mayor pregunta: ¿de qué manera pudieron los líderes políticos wari convocar y controlar la mano de obra para llevar a cabo los propósitos del Estado? Para contestar a esta pregunta se examina y compara el uso del espacio en muchas de las viviendas excavadas en Cerro Mejía, sitio wari de tercer nivel en la jerarquía del Imperio (segundo de la región).

Varios investigadores han sugerido que la administración wari se instaló dentro de una esfera residencial, como en las estilizadas construcciones monumentales denominadas grupo-patio (Isbell, 1991; McEwan, 1991; Spickard, 1983; Schreiber, 1992). Debido a que todas las estructuras residenciales en Cerro Mejía consisten en recintos asociados a patios, aquí se utilizará el término «grupopatio wari» para referirse a las estructuras formales que se parecen a estas formas diagnósticas de organización espacial. En el pasado, las construcciones grupopatio fueron utilizadas para identificar los centros administrativos estatales (Isbell, 1989). En investigaciones recientes, y como consecuencia de las interpretaciones mencionadas anteriormente y su importante potencial político, estas organizaciones

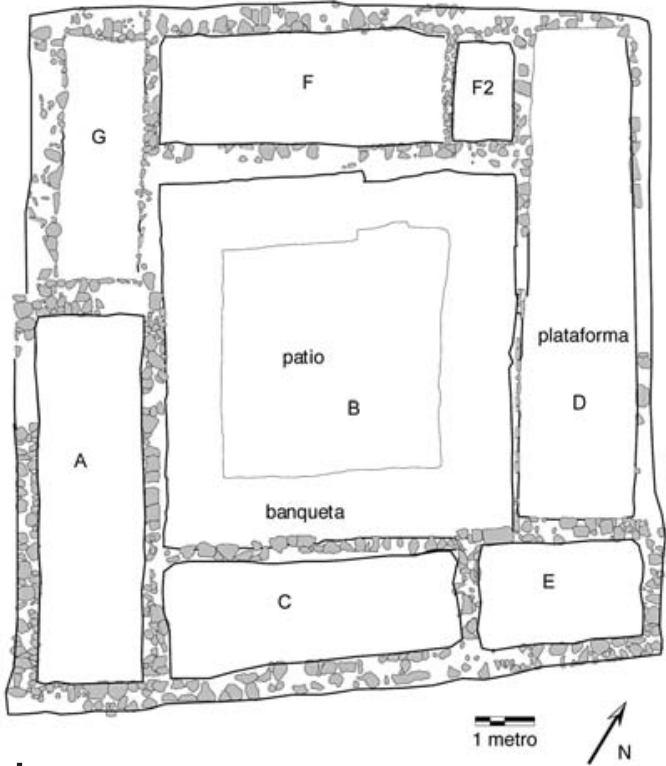

Figura 2 - Plano de la unidad 9, un grupo-patio wari, en la cima del Cerro Baúl espaciales han recibido gran atención (Isbell \& McEwan, 1991).

Un típico grupo-patio wari construido al estilo de los hallados en la capital situada en Ayacucho, tiene un patio abierto rectilíneo o trapezoidal, rodeado en tres o más de sus lados por recintos rectangulares adosados a la pared perimetral externa (fig. 2). Estas estructuras tienen gran variación en el número de recintos, tamaño del patio y naturaleza de los artefactos asociados recuperados durante las excavaciones. Los grupo-patio wari han sido identificados como residencias de elite, pero no todos los edificios con esta forma pueden ser asociados a esta función (por ejemplo, la cervecería ubicada en Cerro Baúl [Moseley et al., 2005] y algunas estructuras similares en Azángaro que no exhiben basura residencial) (Anders, 1991). Pero es significativo que muchos grupos-patio 
wari con basura residencial también presentan materiales que podrían estar asociados a festividades (Glowacki, 2002; Cook \& Glowacki, 2003; Isbell, 2004; 2007; Isbell et al., 1991).

Los grupos-patio wari de Cerro Baúl presentan una construcción de alta calidad. Los muros están construidos con una mampostería fina de piedra de doble cara, caracterizados por rellenos de cascajo y un fino mortero con inclusiones de grava. Estas residencias fueron construidas con algunas piedras labradas y en cierta medida son monumentales. En el Sector A, el grupo-patio wari parece ser la residencia principal dentro de un palacio residencial (Nash, 2011) (fig. 3) y del patio central se recuperaron más de 60 vasijas rotas correspondiendo a restos de fiestas. Este patrón de uso es similar a los hallados en Moraduchayoq (Brewster-Wray, 1989; Isbell et al., 1991) y más recientemente en Conchopata (Isbell, 2004; 2007; Isbell \& Groleau, 2010). A pesar de que los restos de Cerro Mejía son menos monumentales, este es considerado como un centro administrativo pequeño, porque tiene dos edificios centrales localizados en la cima y se asemeja al estilo grupo-patio wari (fig. 4). La mampostería de Mejía es menos sofisticada en la construcción pero el material constructivo y el tamaño de ambos complejos debió requerir una gran inversión en mano de obra destinada a la construcción y estuvo ocupada por administradores estatales de bajo rango. Otras estructuras residenciales en Cerro Mejía no muestran la típica organización del grupo-patio wari, pero consisten en recintos rectangulares o cuadrangulares que encierran un patio.

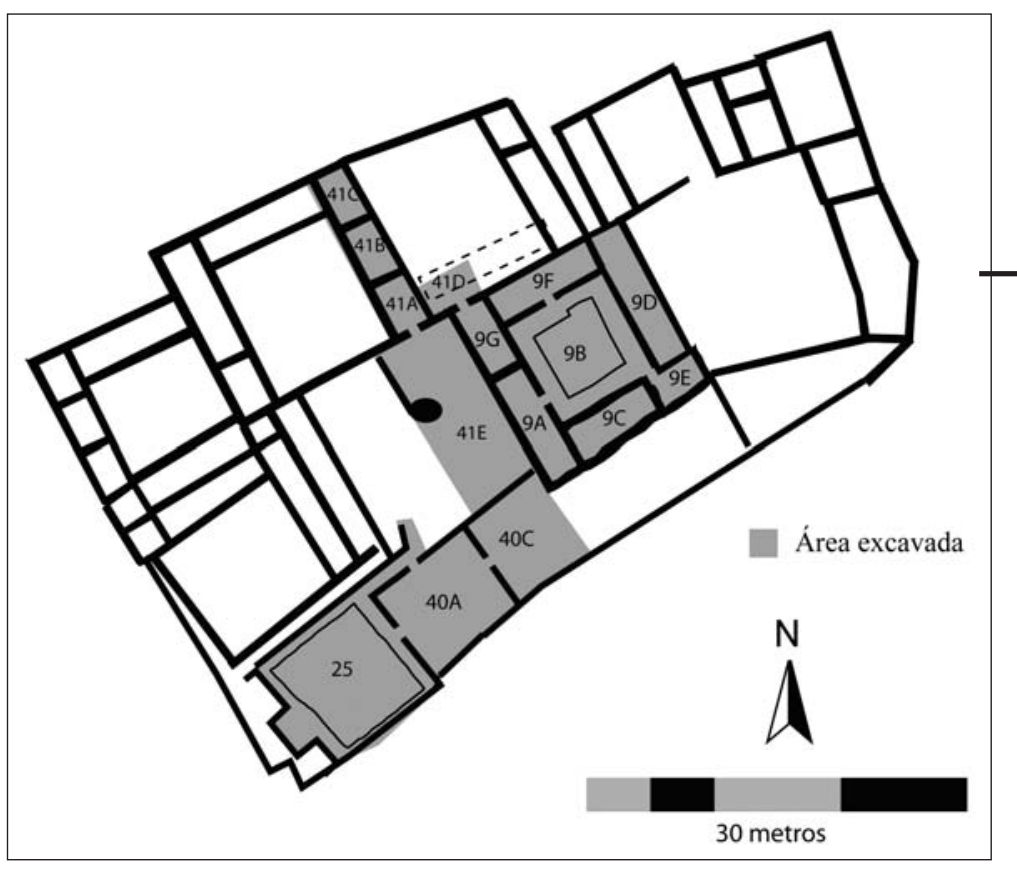

Figura 3 - Mapa del palacio de Cerro Baúl en el Sector A

Una sala de entrada (25); un taller de cerámica (40A); un jardín (40C); un grupo-patio wari usado como residencia (9A-G); un aterrazamiento para la preparación de alimentos $(41 \mathrm{~A}-\mathrm{C})$; un patio con evidencia de actividades productivas (41E) 


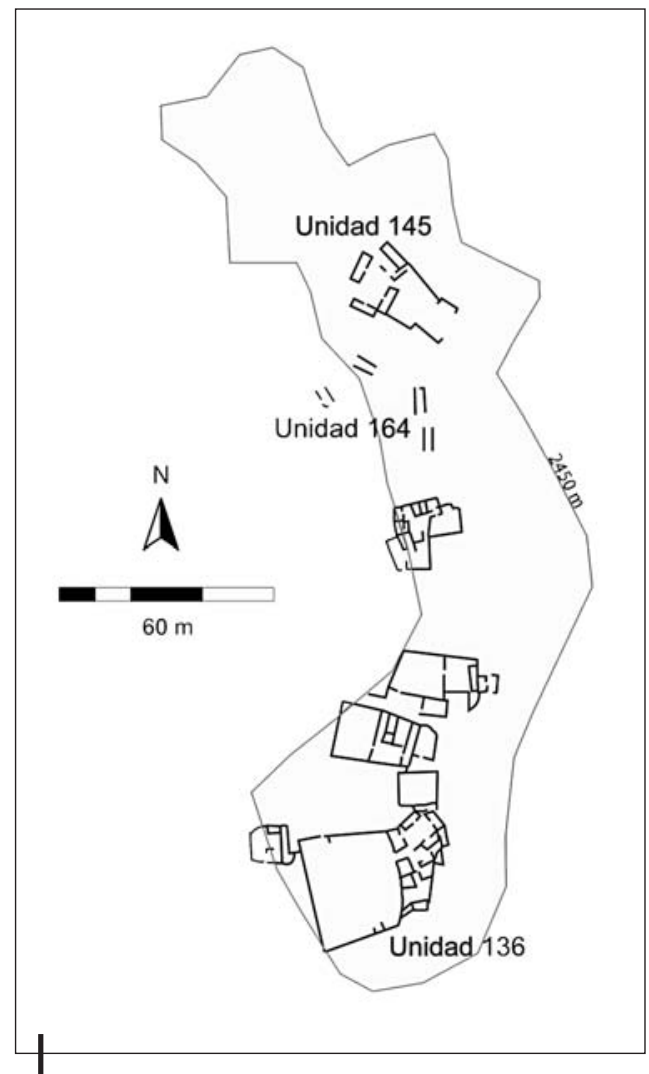

Figura 4 - Mapa de los edificios ubicados en la zona central de la cumbre de Cerro Mejía
Con el propósito de recolectar un amplio número de muestras de diferentes estructuras residenciales y de sus elementos asociados, se excavó un grupo de recintos en la pendiente aterrazada del cerro y en recintos de mayores dimensiones ubicados en la cima. A partir de estas excavaciones, se esperaba obtener un mejor entendimiento general de las unidades domésticas y de las prácticas administrativas especializadas a través de la comparación del uso del espacio de viviendas con patrón grupo-patio wari y otras viviendas. La sociedad wari fue estratificada, compuesta de diversos grupos o clases, tales como administradores, sacerdotes, artesanos, pastores y campesinos. Es por ello que si la administración wari se ejerció dentro de un entorno doméstico (Isbell \& McEwan, 1991; Schreiber, 1992), esta puede ser clasificada como una especialización doméstica. Y en este caso, las correlaciones arqueológicas de los tipos de relaciones políticas y de control social, así como otras especializaciones (por ejemplo, la producción cerámica), también deben estar presentes junto a las actividades domésticas estandarizadas.

Las excavaciones llevadas a cabo en Cerro Mejía muestran un gran contraste en el uso del espacio residencial entre estructuras asociadas al grupo-patio wari y las residencias que no presentan esta asociación. Estas diferencias deben derivarse de la administración o de las actividades políticas de los líderes y/o administradores. Este artículo describirá las actividades, los rasgos arqueológicos y los aspectos espaciales de las actividades políticas residenciales llevadas a cabo en Cerro Mejía. Pero, antes de comenzar, se discutirán algunos conceptos teóricos significativos que se refieren a este modelo. También se revisará la organización de la administración inka, que brinda las bases interpretativas de esta investigación.

\section{ESPACIO RESIDENCIAL Y ACTIVIDAD DOMÉSTICA}

El espacio está definido por la acción (Rapoport, 1990). Asimismo, está designado a permitir que se lleven a cabo ciertas actividades (Norberg-Schulz, 1985). Por lo tanto, la gente crea el espacio y el espacio determina a la gente, ambos son interactivos y se modifican uno al otro de una manera dialéctica (Ardener, 1981; Bachelard, 1969; Douglas, 1973; Kent, 1990). El espacio es el uso llevado a cabo 
dentro de ambientes construidos y está físicamente constituido por construcciones arquitectónicas. Previas investigaciones arqueológicas llevadas a cabo en los Andes han vinculado vivienda a etnicidad (Aldenderfer, 1993; Stanish, 1989; 1992).

Los espacios residenciales han sido descritos como «una visión del mundo plasmada en pequeño» (Rapoport, 1969: 2). En algunas sociedades, las viviendas son utilizadas como metáforas del mundo natural o sobrenatural (por ejemplo, la casa Ainu [Ohnuki-Tierney, 1972]; la longhouse iroquesa [Tooker, 1978]; la casa Berebere [Bourdieu, 1979]). Dejando de lado las asociaciones obvias, las viviendas son participantes activos de las relaciones familiares y comunales. Una vivienda es una «estructura estructurante» (Bourdieu, 1977: 90; véase también Donley-Reid, 1990; Giddens, 1979; 1981). Arqueológicamente, estas pueden ser consideradas como grandes artefactos que materializan los aspectos económicos, políticos e ideológicos de los individuos que habitan dentro de ella. En general, los ambientes construidos determinan muchas actividades y las viviendas «no son reflejos pasivos de la interacción social, sino más bien los contextos que estructuran esta actividad» y otro tipo de actividades (Tringham, 1991: 106). Por lo tanto, las viviendas son artefactos diseñados y sus formas demuestran intencionalidad; es así que los artefactos y los ecofactos pueden ser utilizados para entender las intenciones. En ciudades o comunidades pequeñas, los espacios se extienden dentro del paisaje percibido y es a través de su uso como medio social que tanto las características topográficas como las estructuras construidas afectan la actividad humana. Los niños dentro de una sociedad aprenden el tipo de actividad que pueden llevar a cabo dentro de la casa (Hall, 1981; Oliver, 1990). En la medida en que los niños se aventuran a explorar espacios públicos, o al exterior de la casa, experimentan los lugares en asociación con diferentes tipos de relaciones sociales, experiencias que les servirán de guía para futuras interacciones (Bourdieu, 1977: 214; Pader, 1988).

En una sociedad compleja, el desarrollo institucional debe estar asociado a estándares de formas arquitectónicas. A partir de esta asociación, los arqueólogos podrían examinar y definir un conjunto específico de actividades o una categoría de acción en asociación a una forma espacial (Nash \& Williams, 2005). Estas actividades pueden ser residenciales, administrativas, ceremoniales o sagradas, aunque tampoco debieron de ser excluyentes entre sí. En un Estado o Imperio, estas instituciones deben de haber dejado evidencias semejantes, porque aunque estas pueden haber sido realizadas por miembros de diferentes grupos culturales, los individuos al servicio del Estado requieren de un sistema relativamente unificado que tome en cuenta un medio y un tipo de comunicación, así como de prácticas (Morris, 1995). Las ceremonias de manejo estatal debieron ser reconocidas y entendidas entre los miembros del gobierno estatal (Scott, 1998).

Un Estado no puede controlar una región sin la existencia de interacciones directas entre los miembros del gobierno central y los líderes locales. Algunas de estas interacciones directas pudieron haberse llevado a cabo en la capital o en los centros administrativos. De esta manera, y a través de la experiencia, los líderes regionales y locales aprendieron a participar en actividades dentro de espacios 
wari como miembros de la jerarquía política. Así, estos ambientes construidos obtienen significado, y a su vez, estructuran actividades.

Es así que los líderes locales habrían recibido cierto conocimiento tecnológico para poder ejercer como administradores wari (Dobres, 2000; McGaw, 1996). Tanto el contexto espacial como los funcionarios presentes impusieron el carácter de las actividades (Rapoport, 1990). Es por ello que, probablemente, los líderes locales incorporados al imperio fueron los que trasladaron a sus comunidades los patrones de actividades asociados al manejo estatal. Pero en el contexto local, estos líderes debieron haber modificado estas actividades o adoptado una combinación de prácticas tanto locales como foráneas, formando nuevas tradiciones de gobierno o liderazgo. El punto clave es que esos lugares adquieren definiciones culturales a través de su uso, y la gente usa los objetos materiales basados en sus experiencias del pasado. Así, construir un medio ambiente toma significado, y estos contextos estructuran las actividades. Después de todo, las personas modifican sus prácticas dependiendo del tipo de contexto social en el que se encuentran. Asimismo, el mismo grupo de personas puede utilizar diferentes maneras de comportamiento (Gero \& Scattolin, 2002). Dejando de lado la manera en que las prácticas estatales impactaron el comportamiento de los líderes locales, no se conoce la forma en que las interacciones estatales-locales debieron de haber impactado en las instituciones administrativas locales, así como en sus contextos espaciales.

\section{CONSIDERACIONES SOBRE LAS ESTRUCTURAS DOMÉSTICAS DE CERRO MEJÍA}

En una sociedad compleja que cuenta con múltiples especialistas, diferentes niveles de estatus y presencia de enclaves multiétnicos procedentes de muchas regiones, tal como era el caso del imperio wari, el uso del espacio residencial debió haber variado en gran medida (Bawden, 1990). La organización de actividades dentro de una vivienda puede variar en su forma y las diferencias dentro de una vivienda no necesariamente impactarían en las actividades fuera de esta. Es así que para una sociedad el concepto de espacio residencial puede incluir actividades que no están asociadas al consumo familiar. Una de las metas de la investigación en Cerro Mejía fue lograr comprender qué estaban haciendo las personas en sus viviendas. Las actividades reflejadas en hallazgos y restos artefactuales fueron comparadas entre las estructuras residenciales intervenidas. En las fases iniciales del análisis se enfatizaron las similitudes pero también se documentaron las diferencias. Asimismo, al comparar las funciones de los artefactos recuperados, se distinguieron patrones de actividad. Las herramientas y otros objetos se agruparon por tipos de actividad, y asimismo algunos hallazgos como los fogones mostraron asociaciones a un limitado conjunto de artefactos. Los patrones presentes en los contextos residenciales fueron definidos como actividades domésticas comunes y la recurrencia de patrones domésticos comunes dentro de una sola estructura fue tomada como indicador de la presencia de más de un grupo doméstico dentro de la vivienda. 
Las casas fueron definidas como construcciones contiguas que compartían una entrada común (pero había estructuras que fueron contadas como casas separadas aun cuando compartían una entrada común, ya que para acceder al otro cuarto se tenía que salir del recinto). Los miembros de una unidad fueron aquellos que contribuyeron con el conjunto de materiales hallados en la habitación. La muestra disponible es muy pequeña para indicar la naturaleza de la organización familiar en Cerro Mejía. Sin embargo, el término «familia» está asociado a la presencia de zonas de cocina con fogones, y su repetición al interior de una habitación fue interpretada como evidencia de un grupo de parentesco compuesto de múltiples familias (Stanish, 1989; Weismantel, 1988). Estos grupos familiares pueden representar un agregado de familias nucleares, una familia extendida de varias generaciones o matrimonios polígamos con múltiples esposas en donde cada una poseía su propia área de cocina. La presente muestra evidencia que si bien el conjunto de actividad cocina/fogón estuvo espacialmente separado en viviendas con múltiples subunidades familiares, otras actividades productivas y el consumo de comidas fueron frecuentemente llevados a cabo en espacios abiertos y compartidos.

Aunque la altura de las paredes de los patios es incierta, todas las casas de esta muestra incorporan habitaciones cerradas (techadas o que delimitan espacios interiores) y patios que fueron claramente delimitados por muros (espacios exteriores). Los conceptos básicos que dividen el uso del espacio entre la actividad interior y la exterior no fueron compartidos entre estas unidades en todo el sitio. La organización de las actividades es variada, sin embargo, el conjunto de actividades básicas sugiere que la gente llevaba a cabo tareas similares en sus casas (Nash, 2002). La estructura de las casas (el tamaño y la calidad de construcción) y los artefactos asociados a estas fueron utilizados para sugerir el estatus sociopolítico entre las unidades domésticas. El concepto de espacio residencial representado por la disposición de los restos de artefactos en los conjuntos domésticos menos elaborados, fue comparado con el rango de actividades presentes en las estructuras formales del grupo-patio ubicadas en la cima de Cerro Mejía.

Dado que el espacio es diseñado y construido alrededor de las actividades, y los tipos de espacios y sus actividades asociadas son culturalmente determinadas, surgen algunas ideas al respecto. Teóricamente, si los miembros de un hogar agregan una actividad a las actividades que cotidiana y repetidamente llevan a cabo dentro de su espacio residencial, la casa debe ser modificada para acomodar el nuevo conjunto de actividades. Esta modificación debe tomar la forma de un nuevo rasgo que se agrega al espacio existente, o bien requiere de la adición de nuevo espacio o la reformulación del espacio existente. La remodelación permite al hogar incorporar actividades extras de producción o reproducción. Este sería un paso natural en el ciclo de vida en un hogar. Por ello, cuando los niños crecen y se casan, la organización del hogar debe cambiar para incluir nuevos miembros (Goody, 1972). La remodelación también puede ser un indicativo de producción artesanal o de la adquisición de una nueva ocupación especializada en el hogar. Por supuesto que no todas las actividades artesanales 
pudieron haber sido incorporadas en el espacio residencial, sin embargo, la investigación demuestra que algunos aspectos de la administración fueron fácilmente añadidos a los espacios de vivienda. La extensión o elaboración de la modificación espacial puede estar relacionada con la importancia del nuevo conjunto de actividades. Por el contrario, si un hogar ha llevado a cabo tradicionalmente una producción extradoméstica, estas actividades se habrían acomodado al diseño y construcción original de estos espacios residenciales. En otras palabras, si equiparamos la administración a cualquier tipo de especialización (por ejemplo, la producción cerámica) tomando en cuenta que los Estados del Nuevo Mundo tenían especialistas a tiempo completo y que estos artesanos trabajaban en sus casas, se puede argumentar que dedicar un espacio de trabajo a labores de producción artesanal no dista de aumentar una plataforma y un espacio para la producción de chicha que se encuentre dentro de una casa que, a la vez, mantenía relación con la administración.

El modelo actual sobre cómo una residencia de grupo-patio wari fue utilizada por miembros de elite de la sociedad Wari, incorpora tanto la actividad residencial como la administrativa (Isbell, 1991). A pesar de que para entender el sistema espacial wari se tuvo que aislar rasgos espaciales y contextos arqueológicos asociados a propósitos divergentes, esto sirvió para determinar en qué consistió la administración de esta elite y qué componente de una residencia administrativa estuvo asociado a esta actividad. Acá comparo las casas de las personas del común con las que habitaban en los grupos-patio wari para tener un mayor entendimiento de los tipos de actividades que los líderes de Cerro Mejía adhirieron a su casa para realizar tareas de administración estatal. La diferenciación entre las formas residenciales debieron ser necesarias para poder llevar a cabo funciones administrativas o simbólicas.

Algunos investigadores sugieren que los líderes locales pudieron imitar las formas de las casas wari como signo de su poder simbólico. En el caso de Moquegua donde se encuentra ubicado Cerro Baúl, que es un lugar situado por encima de cualquier otro sitio de la región, estas estructuras no pudieron ser copiadas sin tener un conocimiento íntimo del interior de las residencias de elite del sitio. En tal caso, dada la altura de los muros, y la distancia de cualquier otro sitio wari, se sugiere que ningún líder local haya podido copiar una casa wari sin haber tenido que pasar gran parte del tiempo dentro de una de ellas o habiendo tenido que ser parte de los grupos de trabajadores que la construyeron. Por ende la gente que tuvo poco contacto con los wari no pudo construir viviendas de formas similares. También se sugiere que lo observado en Cerro Mejía y Cerro Baúl refleja de manera cercana lo que estaba ocurriendo en la capital wari. Debió haber existido una cercana conexión entre el centralizado Estado wari y la gente que fundó la colonia wari en Moquegua, establecida a través de la interacción. Si otras investigaciones se enfocaran en las actividades residenciales en sitios wari de diferentes regiones del Perú, estos deberían encontrar patrones similares a los presentados en este trabajo. En el caso que los patrones mencionados no estuvieran presentes, las investigaciones representarían una base de datos sólida refutando el control wari 
en la región de Moquegua, lo que la cerámica de prospecciones y/o pequeños pozos de cateos actualmente no brinda.

\section{LA NATURALEZA DE LA POLÍTICA WARI}

La colonia wari, en Moquegua, fue un asentamiento estatal intrusivo. Los edificios, la distribución de la organización espacial y los artefactos no tuvieron antecedentes locales. Algunos investigadores debaten para saber si Wari fue un imperio; al respecto, en Moquegua existen muchas evidencias que señalan a los wari como una organización política expansiva (Nash \& Williams, 2009). Esto no sugiere que Wari fuera un imperio en todos lados (donde hay fragmentos cerámicos), pero sí en algunas áreas de Moquegua (y el valle de Carahuarazo [Sondondo]) (Schreiber, 1992; 2001; 2005) que además demuestran una mayor transformación que solo puede ser explicada si lo wari fuese una entidad expansiva. Sin embargo, este proceso de expansión aún no está bien entendido, pero para manejar y administrar un imperio en expansión, los líderes wari debieron haber desarrollado instituciones y tener personal para controlar los múltiples recursos y diversos grupos de gente antes de su expansión. Se sugiere que Wari operó política y económicamente a través de una jerarquía de administradores que manejaban una variedad de recursos y productos (Nash \& Williams, 2009). Históricamente muchos imperios han sido organizados jerárquicamente (esto es, la Roma republicana tardía [Badian, 1968]; los inkas [Rostworowski, 1999]; los aztecas [Evans, 2004]; etc.). Muchos sistemas políticos expansivos combinan relaciones jerárquicas directas, coercitivas e indirectas para obtener el control en una amplia esfera de control e influencia (Schreiber, 1992; Sinopoli, 1994). Es probable que el sistema político wari se articulara con algunas regiones a través de una relación política asimétrica o de control coercitivo indirecto. No obstante la evidencia encontrada en la colonia de Moquegua sugiere una relación jerárquica directa con administradores de Ayacucho que ocupaban Cerro Baúl (Moseley et al., 1991; 2005), pero es aún incierta la procedencia de la gente viviendo en Cerro Mejía (Nash, 2011).

«Administración» es un término impreciso que abarca una diversidad de interacciones. Este término permite a los arqueólogos abordar cómo la interacción política directa o «de persona a persona» fue ejecutada y preguntarse cómo los intercambios económicos fueron negociados. Los modelos de administración andina derivan de los relatos etnohistóricos del imperio inka y están instituidos en principios de reciprocidad que motivan intercambios asimétricos entre patrones y servidores (D'Altroy, 2002; Moseley, 2001; Murra, 1980). Las teorías acerca de la administración wari se acercan a las descripciones del proceso inka y a la etnografía andina (Isbell, 1978). Los sistemas políticos wari e inka están separados por unos 100 años y parece altamente improbable que estuvieran organizados de la misma manera. Por otro lado, el sistema político expansivo wari duró casi cuatro siglos y si nosotros comparamos su organización en el 600 d. C. con su pérdida de control global alrededor del año 1000 d. C., las instituciones, su organización y actividades administrativas asociadas están significativamente diferenciadas (Nash \& Williams, 
2005; Williams \& Nash, 2002). No obstante, si son realizadas con cautela se puede observar similares manifestaciones materiales entre la expansión política inka, la cual es conocida etnohistóricamente, y la política wari que es prehistórica.

\section{UNA HIPÓTESIS SOBRE LA ORGANIZACIÓN POLÍTICA INKA}

Los modelos de gobierno inka están enfocados en los principios de reciprocidad. El intercambio ocurrido entre oficiales estatales y poblaciones subyugadas pueden ser entendidos como diferentes tipos de relaciones complejas ocurridas entre la administración inka y los grupos subordinados (Costin, 1998; Gose, 1996; Rowe, 1982). Muchos autores han vinculado la administración a las festividades (Gero, 2001; Isbell, 1978; Morris, 1982; Murra, 1980). Los agasajos y la entrega de obsequios fueron usados para crear relaciones entre los líderes y los subordinados, definiendo las obligaciones entre los anfitriones y sus invitados (Dietler, 2001). El primer método para la extracción de recursos fue a través de la contribución del tributo laboral denominado m'ita (Murra, 1982). La m'ita fue una obligación familiar de trabajo para contribuir con el Estado. Este servicio fue pagado a través del trabajo en los campos de cultivo pertenecientes al Estado y/o de la religión estatal, pero también podía ser a través de la minería, pastoreo, ejército o servicios de mensajería, y otras labores especializadas (Rowe, 1946). Los inkas proveían de comida a los individuos que trabajaban para los proyectos del Estado y también de artículos domésticos o vestimenta para los trabajos que se realizaban fuera de sus regiones (Betanzos, 1987 [1557]). Por consiguiente, las comidas caracterizaron dos aspectos de la relación entre los administradores y sus administrados. En primer lugar, las comidas que formaron parte de los agasajos o festines establecieron relaciones sociales, y en segundo lugar, la distribución de comida fue parte de la contribución del Estado a las personas que otorgaron el tributo de trabajo (Nash, 2011).

Los festines fueron actividades importantes de muchos proyectos estatales (Rostworowski, 1999). Los inkas usaron diferentes tipos de instituciones para mantener su control político y extraer los recursos de las poblaciones subordinadas. Las áreas espaciales de estas acciones son igualmente diversas. Los centros provinciales wari exhibieron muchos tipos de formas arquitectónicas, y por lo tanto parece que diferentes construcciones monumentales representan un conjunto de instituciones del Estado wari (Nash \& Williams, 2005). Sin embargo, sitios de menor rango que los centros provinciales no tuvieron una gran diversidad de formas arquitectónicas. Así estos espacios pudieron haber sido modificados para que las actividades fueran llevadas a cabo en espacios menos elaborados o simplemente estas actividades no fueron llevadas a cabo debido al limitado poder ejercido por los administradores de menor jerarquía.

Dado que el imperio inka fue documentado en relatos etnohistóricos, y debido a que su centro político estaba organizado de manera administrativa, el gobierno inka puede servir como punto base de comparación e inferencia, especialmente 
tomando en cuenta que el Cuzco fue una provincia que estuvo bajo la influencia wari por un largo periodo de tiempo. Se describirá brevemente la jerarquía Inka para demostrar la profundidad con que penetró el Horizonte tardío y su potencial impacto en las comunidades y en las unidades domésticas (D'Altroy \& Hastorf, 2001).

Cada una de las «cuatro partes» del Imperio inka tenía un gobernador quien estaba al servicio del Sapa Inka. Las provincias inkas Ilamadas huamani (Santillán, 1950 [1563]) — hubo aproximadamente unas 80 (D'Altroy, 2002)—, idealmente contenían 40000 unidades de impuesto o familias y eran administradas por un individuo, quien debía mantener dos residencias, una en Cuzco y otra en la provincia bajo su cargo (Morris \& Thompson, 1985; Zuidema, 1990). A este nivel algunos administradores de grupos más pequeños fueron líderes indígenas (locales o no inkas) que controlaban poblaciones de diversos tamaños que fueron dejados en sus lugares para continuar manejando sus respectivos territorios cuando estos cooperaban con el imperio. En el prototipo del sistema decimal inka, el administrador de 10000 unidades familiares formaba una unidad Ilamada huaranga (Julien, 1982), y participaba en los rituales del Estado (Bauer, 1996). Ellos parecen haber sido del nivel más bajo de la elite noble en Cuzco. Las elites menores estaban compuestas del Pachaca Curaca, quien controlaba los recursos laborales de 100 familias y parecen haber sido participantes importantes en el territorio wanka (D'Altroy, 1987). Finalmente, el Chunca Curaca era responsable de grupos de 10 familias (Rostworowski, 1999). Parecería que estas elites menores participaban en proyectos laborales locales, sirviendo como supervisores.

\section{UN MODELO ESPACIAL DE ADMINISTRACIÓN RESIDENCIAL}

Las excavaciones de un asentamiento incorporado directamente dentro de una jerarquía con una estructura similar a la organización inka, deben revelar facilidades donde se realizaron pequeños agasajos, y en el cual los líderes de diez familias (una comunidad pequeña o grupo de parentesco) celebraban fiestas modestas para los jefes de familia debajo de la jerarquía sociopolítica. Este espacio debió estar acompañado de vasijas especialmente utilizadas para el servicio y consumo durante las festividades, aunque probablemente a este nivel solo debía haber una copa o vasija especial debido a que la tradición andina de servir y beber se realiza por turnos y de acuerdo a rangos (Bolin, 1998; Meyerson, 1990). De acuerdo a esto, solo algunos objetos del Estado deberían ser encontrados en las casas de estos administradores, y tal vez en otras casas.

Dependiendo del tamaño del asentamiento también debió haber estructuras de similar tamaño para el Pachaca Curaca (líderes regionales), en donde realizaban fiestas y otorgaba regalos a sus subordinados. Si estas actividades socioadministrativas tuvieron lugar dentro de la residencia del líder, el espacio del patio de un líder regional debió ser lo suficientemente grande para organizar una reunión, quizás tener un patio extra o una plaza contigua que debió ser construida como local para 
realizar estos eventos. Las esposas del líder y otras mujeres de la familia debieron atender en la fiesta. Seguramente también fue requerido un almacén de pequeña escala donde se guardaban provisiones extras para el evento y los regalos, denotando el estatus elevado del líder local.

Estos eventos, que se realizaban de manera ocasional e involucraban la preparación y organización de festividades, no fueron la principal ocupación de los administradores de menores niveles jerárquicos, y los medios para la realización de los festines tampoco fue el principal propósito de la estructura arquitectónica. La labor doméstica y las actividades relacionadas a la producción han debido ser la consideración principal en el diseño y construcción de una vivienda. Este diseño pudo haber sido condicionado por conceptos culturales que dictaron comportamientos apropiados para áreas específicas del hogar y algunas prácticas religiosas que debieron haber acompañado una ocupación particular o una identidad ancestral para un individuo (Chacaltana \& Nash, 2009).

Por otro lado, los administradores que estaban a cargo del control de muchas comunidades y probablemente del gobierno de grandes grupos de gente o de provincias enteras, han debido ocuparse de las tareas administrativas de manera diaria. Las actividades relacionadas con la recepción de contribuyentes y elites visitantes, han debido ser parte integral de la posición de estos líderes administrativos. Las estructuras residenciales de estos individuos necesariamente fueron diseñadas en función de estas actividades y en espacios especializados que facilitaban los festejos y la interacción social que son fácilmente reconocibles en el registro arqueológico.

Es por ello que a raíz de un modelo etnohistórico de la administración jerárquica inka, se ha formulado un modelo general de lo que se esperaría ver en los registros arqueológicos de un sitio bajo control imperial directo manejado a través de la reciprocidad. En este modelo, la extracción de recursos era realizada a través de obligaciones personales recolectadas por los líderes locales, usando recursos del Estado como estrategia política para cumplir sus respectivas obligaciones. Por lo tanto, los residuos de los festejos y regalos recuperados dentro de las unidades domésticas no deben representar la retribución del pago por la labor efectuada fuera de la casa, sino reflejar más bien las relaciones y obligaciones ya establecidas entre los anfitriones y los invitados. Estos invitados luego eran obligados a servir en los proyectos del Estado o mandar un representante de su familia para realizar su contribución. Este trabajador ha debido ser alimentado como retribución por su participación en la m'ita, sin embargo, estos eventos de comida han debido realizarse fuera de la esfera residencial (Isbell, 1978; Meyerson, 1990). El Estado también debía abastecer de materiales y víveres a los trabajadores a su servicio, de modo que los miembros de la casa del administrador, particularmente las mujeres de la familia, debieron haber sido las responsables de transformar esos víveres en comida. Por lo tanto, no cualquiera podía ser seleccionado como un administrador de nivel bajo. Sin embargo, para que los administradores participaran de esta forma en la organización estatal debían tener acceso a recursos laborales dentro de sus unidades familiares o de un gran grupo familiar, el cual podía emplear en ocasiones especiales o durante los trabajos de los proyectos del Estado. 


\section{LA COLONIA WARI EN MOQUEGUA}

La impresionante mesa de Cerro Baúl está ubicada entre los ríos Torata y Tumilaca, en la parte alta del valle de Moquegua. Los wari transformaron esta prominente montaña en un centro provincial monumental, ubicado en la frontera sur y aproximadamente a $600 \mathrm{~km}$ de la capital imperial en Ayacucho. Cerro Baúl es majestuoso, pero también nada propicio para construir un asentamiento de cualquier tipo, elevándose a $600 \mathrm{~m}$ del piso del valle. En la cima que ha sido artificialmente aplanada, las estructuras de piedra de la colonia abarcan casi 15 ha. La construcción de este asentamiento representó una notable inversión de trabajo y a su vez una fuente de consumo ya que existió una población que habitó permanentemente en su cima (Moseley et al., 2005). Este centro provincial contenía palacios, templos y estructuras administrativas. Un único acceso de subida hacia la cima sugiere que la entrada pudo haber sido restringida a visitantes imperiales, funcionarios del Estado wari y/o aquellos que servían en este (Williams, 2001; Williams \& Nash, 2002). Tanto Cerro Mejía, Cerro Petroglifo, Pampa del Arrastrado, así como muchos conjuntos de restos residenciales en los flancos norte y oeste de Cerro Baúl, albergaron a la mayoría de los pobladores de la colonia. El extenso sistema de canales incrementó la productividad del área de Torata y canalizó el agua hacia los asentamientos y hacia una gran zona de tierras irrigables ubicadas entre ellos. Un acueducto monumental trasladaba el agua hacia las laderas de Cerro Baúl y luego se dividía para canalizar el agua hacia las laderas del noroeste y de los escarpados terrenos ubicados al sureste, que miran hacia el río Tumilaca. Un pequeño asentamiento denominado El Tenedor, ubicado a lo largo de varias cimas de cerros confluyentes, y un sitio similar pero más pequeño, que aún no ha sido bien documentado, exhiben materiales afiliados a los wari de la cuenca de Tumilaca (fig. 4).

\section{1. Cerro Mejía}

Cerro Mejía es un centro terciario que muestra arquitectura pública, talleres, templos y numerosas estructuras residenciales que varían en tamaño y calidad de construcción (Nash, 2002). Hay poca evidencia de asentamientos en la cuenca alta del río Moquegua antes del Horizonte medio; más aún, la presunción es que todos los asentamientos wari en la fase inicial de colonización fueron traídos específicamente para sostener las actividades estatales en la región. Las estructuras que aquí se discuten tienen fechas radiocarbónicas que las sitúan aproximadamente entre 650 d. C. y 800 d. C. (fig. 5). De este modo, el análisis que sigue corresponde a la fase de ocupación más temprana de wari en el valle de Moquegua definida por Williams (2001) (véase también Nash, 2002; Williams \& Nash, 2002).

Las características constructivas de las viviendas de los trabajadores en el sitio de Cerro Mejía no sugieren que el Estado haya dictaminado la organización y la construcción de las viviendas individualmente. Sin embargo, la circunscripción 
de la cima y la segmentación del área aterrazada ubicada en la falda del cerro, sugieren que el trazado completo del plan de esta comunidad pudo haber sido consecuencia de principios de organización de los sitios wari. Grandes segmentos de pared rodean la cima, creando un claro límite entre los ocupantes del sitio. Una monumental escalinata conecta la cima con los talleres y espacios religiosos ubicados en la ladera sur. Las estructuras residenciales pequeñas fueron construidas en las terrazas domésticas sobre el canal de irrigación, y las laderas están divididas por los restos de grandes paredes en seis barrios residenciales, cada uno con ocho o más viviendas de diferente tamaño.

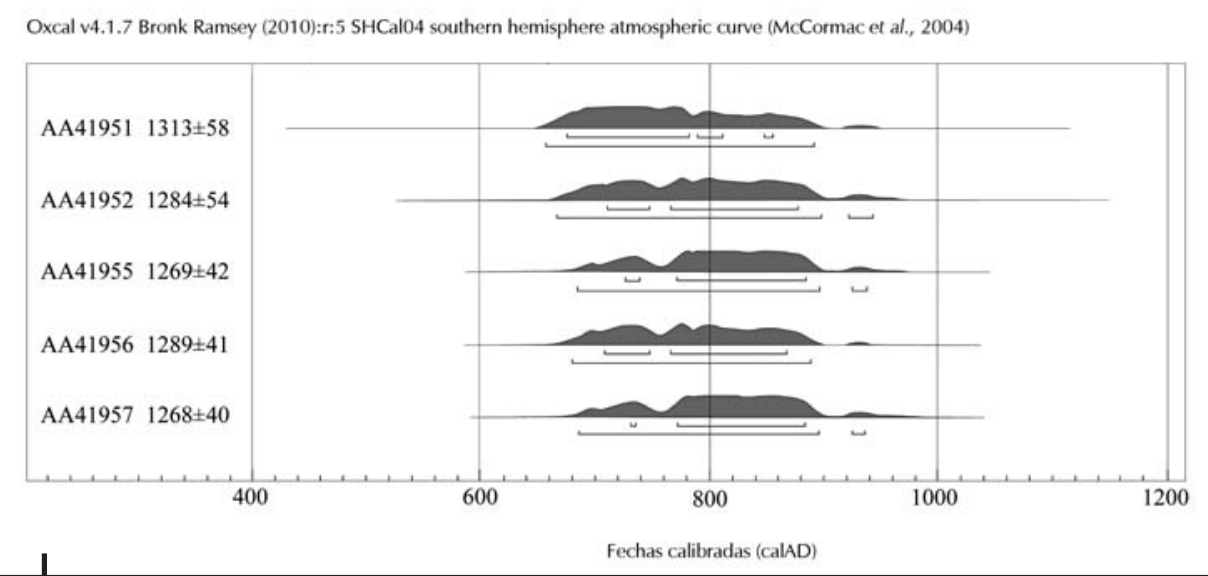

Figura 5 - Fechas calibradas de Cerro Mejía usando Oxcal

\section{2. Las investigaciones}

Las excavaciones realizadas en Cerro Mejía incluyen muchos componentes del sitio y varios contextos. Sin embargo, las investigaciones se han enfocado en las áreas residenciales y se necesitarán investigaciones futuras para evaluar los otros componentes del sitio. La metodología de la investigación incluyó el registro exhaustivo de todos los artefactos hallados in situ, y se usó una malla fina con una apertura de 1,8 $\mathrm{mm}$ para zarandear o tamizar los estratos debajo del sedimento eólico superficial y la ceniza volcánica del Huaynaputina (1600 d. C.) que cubren todos los contextos del sitio.

Aquí, se describirán cinco viviendas y el muestreo realizado en otras dos. Sin embargo, las generalizaciones están basadas en una amplia muestra que va más allá de las excavaciones realizadas en Cerro Mejía. Tres de las casas descritas están ubicadas en los aterrazados situados en las laderas que corresponden a las unidades 3, 4 y 5. Las otras estructuras excavadas estaban ubicadas en la cima de la colina y corresponden a las unidades 118, 136 y 145. La unidad 118 era un 
conjunto de dos casas ocupadas por varias subunidades familiares. Las unidades 136 y 145 son las dos unidades que se asemejan a los grupos-patio wari en Cerro Mejía (fig. 6). El componente formal grupo-patio wari ubicado en la unidad 145 fue excavado de manera extensiva y la unidad 136 representa la estructura más grande, ya que consiste en más de un grupo-patio formal y una gran plaza, la cual fue escogida para ser muestreada y determinar si el componente formal del grupo-patio presentaba actividades similares a las de la unidad 145. Las siguientes descripciones resaltan las más importantes características para reconocer la actividad administrativa y su organización espacial, para una comparación más extensa entre Cerro Baúl y Cerro Mejía (Nash \& Williams, 2009).

Muchas características de los materiales recuperados de Cerro Mejía sugieren que el sitio fue abandonado de un modo planeado y ordenado. En varias

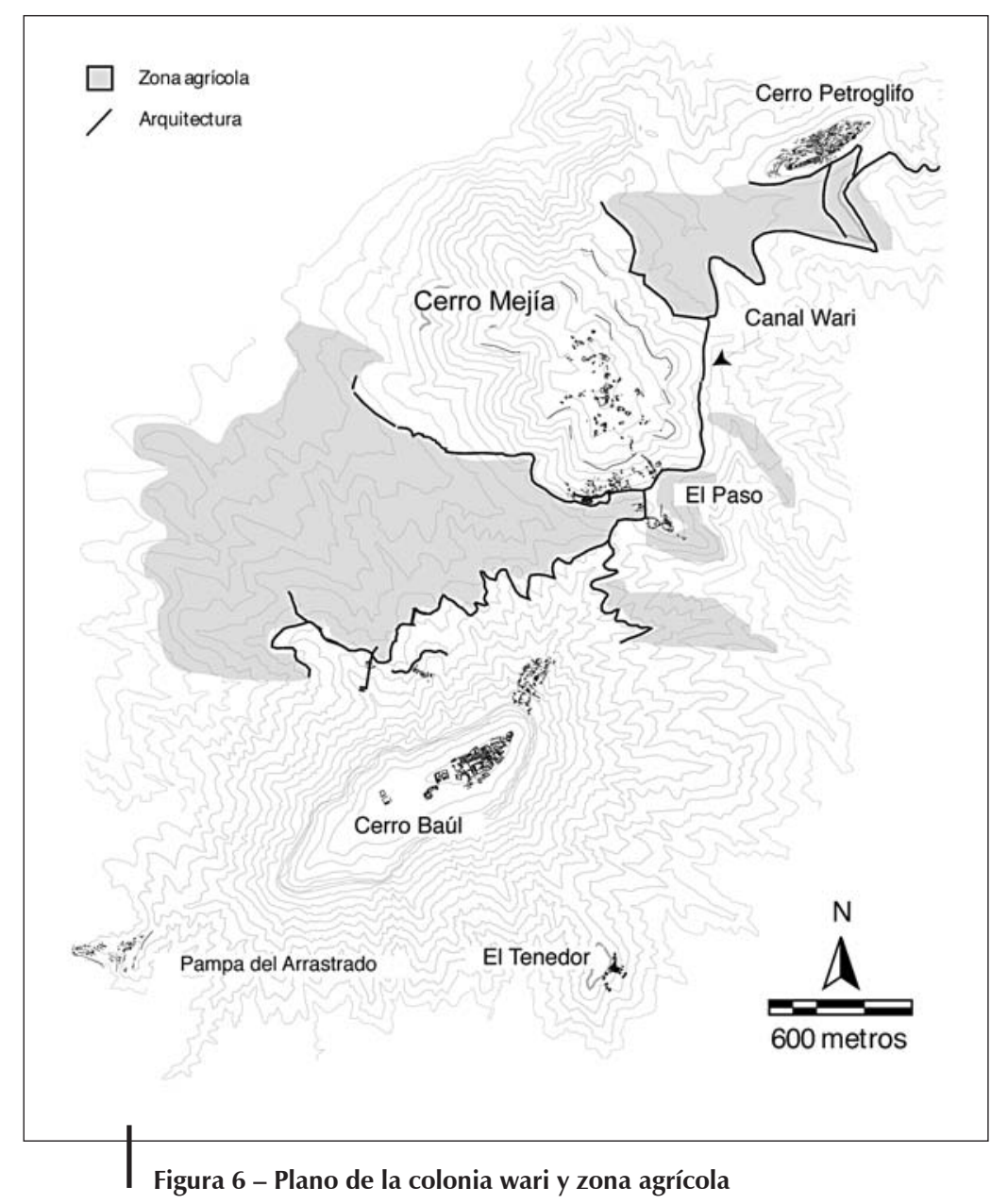


viviendas se encuentran pequeños caches de objetos que estarían indicando que se llevaron a cabo rituales de clausura de las estructuras. Adicionalmente, dentro de las estructuras no se dejaron vasijas completas, y los postes de madera fueron removidos dejando hoyos vacíos; también se abandonaron grupos de objetos incompletos, un general desorden típico de eventos de pre-abandono fue apreciado (Stevenson, 1982). Las estructuras fueron excavadas cuidadosamente para determinar si se podían identificar áreas de actividades.

En todas las viviendas muestreadas se pudo identificar algunos patrones básicos de actividades de producción y consumo. Estas actividades fueron interpretadas a través del registro de la distribución de artefactos dejados sobre la superficie de uso y graficadas durante el trabajo de campo. Una vez identificado el conjunto de herramientas recuperadas in situ de los pisos, se detectaron otras zonas de actividades en base al material zarandeado de las cuadrículas de $1 \mathrm{~m} \times 1 \mathrm{~m}$

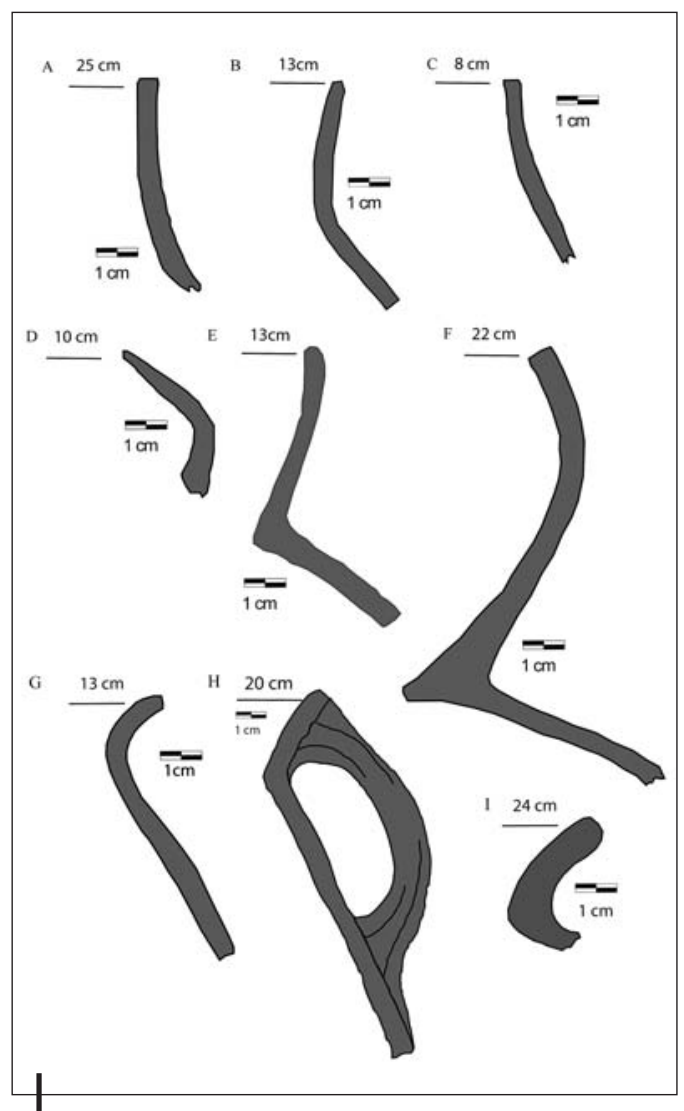

Figura 7 - Bordes de cerámica de Cerro Mejía y Cerro Baúl

(A-F) Son ejemplos de Cerro Mejía que no son típicos de Cerro Baúl; (G-I) son ejemplos típicos wari de Moquegua; (G) es un fragmento de Cerro Baúl; (H e I) son fragmentos de Cerro Mejía excavadas. La recurrente asociación de un conjunto de herramientas utilizadas como parte de una actividad particular, confirmaron la apreciación inicial de que las áreas de actividades de las viviendas abandonadas ubicadas en Cerro Mejía fueran identificadas y recuperadas (para una descripción detallada de un conjunto de herramientas asociadas a estas actividades véase Nash, 2002).

Las vasijas de cerámica fueron clasificadas por pasta y las determinaciones generales de las formas estuvieron basadas en fragmentos diagnósticos. Las pastas pueden estar asociadas a diferentes ambientes de producción o diversos tipos de uso (por ejemplo, las vasijas de cocción contienen generalmente mayor porcentaje de mica). Cerro Mejía tiene gran variedad de pastas y formas de vasijas. Debido a que los cuencos y las ollas de cocinar difieren de forma entre las casas es posible que más de un grupo étnico ocupara el sitio, pero esta hipótesis necesita mayores investigaciones para ser confirmada (fig. 7).

Las herramientas líticas fueron menos variables y el sitio tuvo cuatro formas bifaces (fig. 8). La mayoría de las herramientas fueron expedientes, probablemente debido a que el sitio está sobre una cantera que fue extensamente utilizada durante el periodo Arcaico (Aldenderfer, 1998). El 
material lítico es una importante fuente de información ya que ayuda a determinar las actividades llevadas a cabo dentro de las casas, al igual que los restos de fauna. El material de fauna fue pesado y examinado para determinar los taxa, las huellas de quemado y marcas de corte. Sin embargo, la capa de arcilla en el sitio no dejó material óseo en un buen estado de conservación. Además se recolectó un litro de muestra de tierra de suelo para los análisis botánicos y su identificación, análisis que aún continúan siendo examinados.

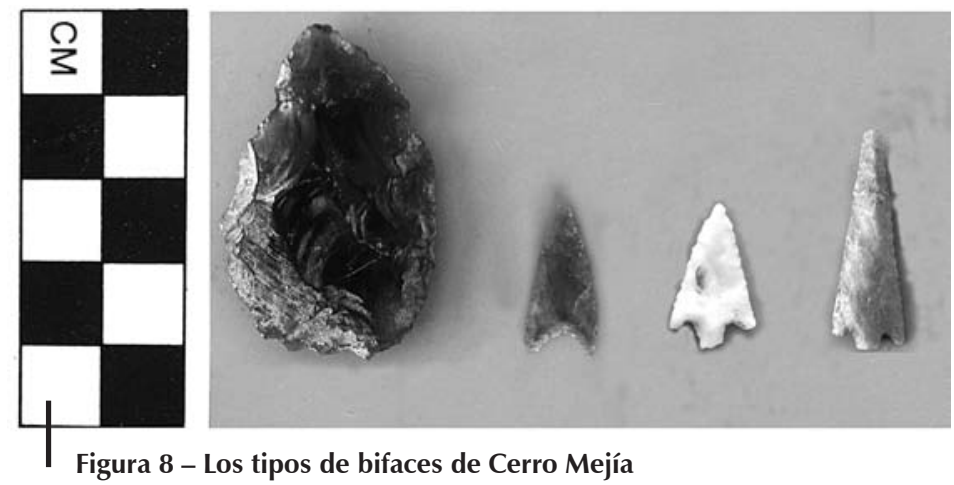

\section{3. Las viviendas}

El modelo básico de vivienda de Cerro Mejía consiste en una pequeña habitación cerrada, levantada con paredes de piedras pequeñas de campo de doble cara enlucidas con barro y con un pequeño patio abierto adyacente circundado por paredes bajas, que debían tener aleros o voladizos que proveían de sombra. La unidad 5, con un solo cuarto y un patio, sirvió de modelo base para entender las actividades domésticas ocurridas dentro de una vivienda (fig. 9A). Al interior de esta habitación había un fogón que contenía 84 pequeñas lascas de obsidiana retocadas, mas la estructura no presentaba bifaces completas, o lascas utilizadas de este material que hayan sido abandonadas. También se encontraron pequeños pedazos de huesos fragmentados que estaban incrustados en la capa del piso. La manufactura de cuentas y la producción de lascas también fueron actividades que ocurrieron en estos espacios.

La evidencia de consumo, tales como cuencos rotos, fragmentos de cántaros y restos de fauna, fueron encontrados predominantemente en el patio, junto con evidencias de actividades productivas. Las herramientas de piedra y sus desechos esparcidos en el piso representan la acumulación de basura como resultado de las actividades. La unidad 5 tenía una banqueta a lo largo de dos paredes del patio, una pequeña vasija de almacenamiento que estaba empotrada dentro de la banqueta, una pequeña laja de piedra que fue hallada junto con dos pigmentos de color. Este artefacto puede representar una actividad de procesamiento; sin embargo, debido a que no se puede probar que haya sido utilizado, este puede 


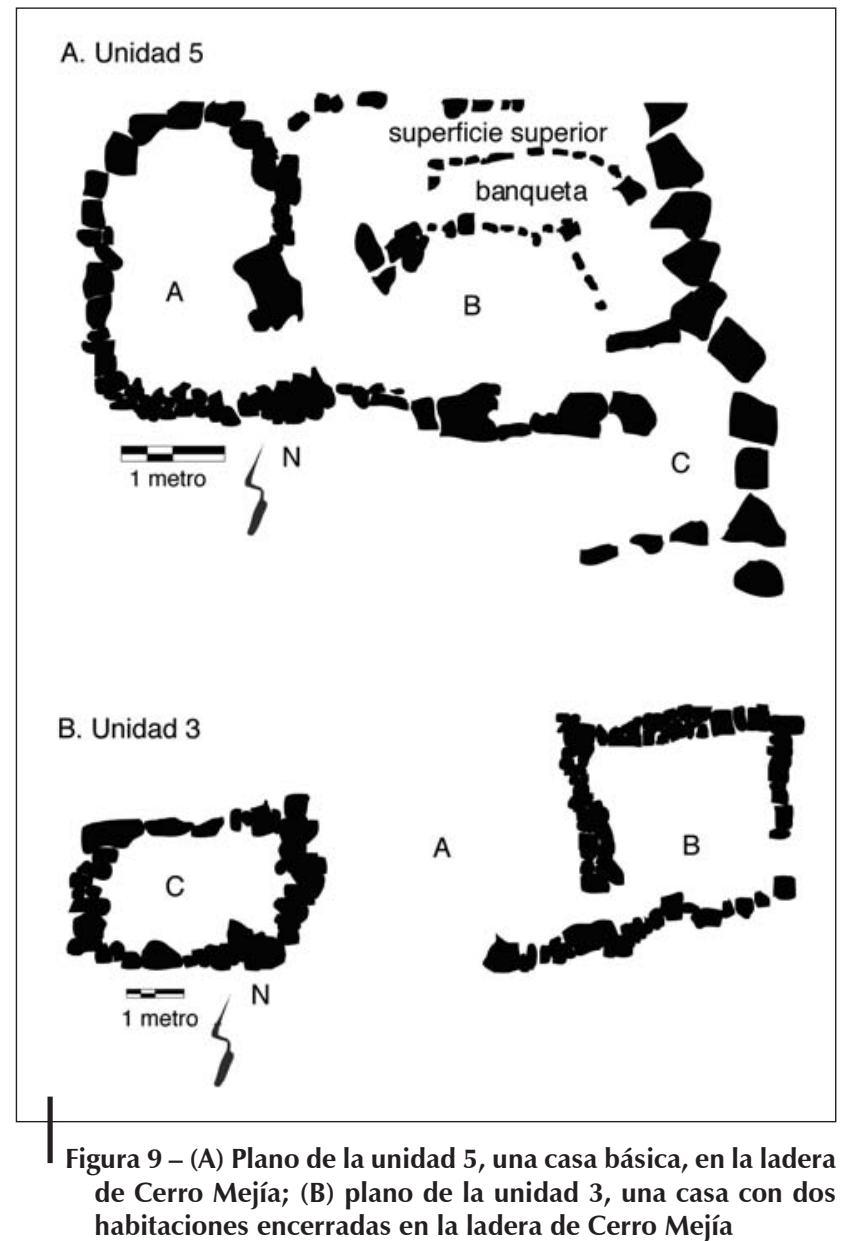

estar relacionado a ofrendas rituales de «placas pintadas» reportadas recientemente en las excavaciones de contextos wari en el valle de Majes y en la región de Chuquibamba (Cardona, 2002; Tung, 2007). Además, recientes excavaciones realizadas en Cerro Mejía permitieron descubrir otra placa pintada confirmando la identificación anterior (Nash \& Barrionuevo, 2009).

Muchas de las viviendas contaban con más de una habitación que compartían el espacio del patio, lo que puede significar la existencia de diferentes tipos de configuraciones familiares. La unidad 3 es un buen ejemplo de la manifestación de este tipo de vivienda, ya que tiene un patio central y una habitación a cada lado (fig. 9B), las cuales muestran similares tipos de artefactos asociados. Ambas presentan huellas de preparación de alimentos, producción de lascas y otras actividades cotidianas, incluyendo la producción de cuentas, herramientas y desechos. El patio fue la principal zona de consumo y el lugar donde se realizaron 
muchas actividades productivas. Se encontró pequeños hoyos llenos de basura que intruían los estratos del subsuelo del patio; este tipo de depósito de basura fue único de la unidad 3.

Habían también algunas viviendas grandes y de arquitectura más compleja. La unidad 4 representa este tipo de edificación, ya que tiene una habitación rectangular cerrada que se puede comparar con los cuartos rectangulares cerrados de las estructuras residenciales ubicadas en las laderas aterrazadas. En esta unidad fue notable la cantidad de huesos de camélidos carbonizados hallados en asociación con un gran fogón de forma irregular. Este fogón tenía casi el doble de tamaño que otros ejemplos excavados y la cantidad de restos de camélidos asociados fue seis veces mayor a lo recuperado en las áreas de cocina en otras viviendas (Nash, 2002; 2010; 2011). Por otro lado, el recinto B que estuvo asociado a la entrada de la estructura, era un espacio en forma de «L» donde el servicio y el consumo de alimentos fueron las actividades dominantes antes de su abandono. Un pequeño recinto, el recinto $C$, ubicado entre el pasadizo de la entrada y el patio, con una pared posterior de forma redondeada, estuvo casi exento de restos excepto por las manchas de yeso blanco y un pequeño depósito de ceniza hallado in situ. Los recintos B y C fueron claramente añadidos a, y modificados de, la estructura original. Además, un área que pudo haber sido un patio fue ampliado a la vez que se construyó una pared redondeada al frente de la construcción original para crear el recinto. El patio que se denominó recinto D presenta una forma típica y tuvo evidencias de muchas actividades productivas cotidianas, así como una pequeña banqueta alineada en la pared posterior. Otra habitación en un nivel de terraza más alto denominado recinto $E$, parece haber tenido un cuarto con fogón de cocina que no fue completamente excavado (fig. 10).

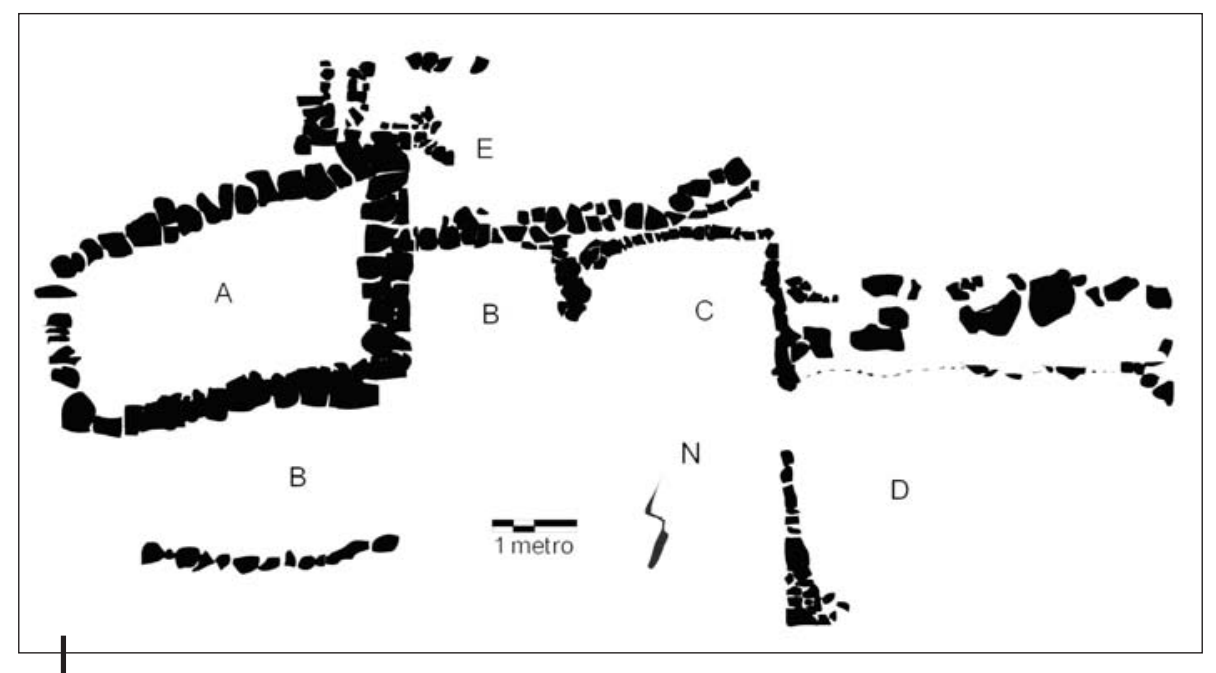

Figura 10 - Plano de la unidad 4, una casa con una sala especial en la ladera de Cerro Mejía 
En los últimos años, unidades domésticas de tamaños similares han sido excavadas, pero en ninguna de estas se ha encontrado la misma cantidad de restos de camélidos (cuarto $\mathrm{A}$ ), el mismo número de cuencos para servir rotos sobre el piso (cuarto B) o se ha ubicado una remodelación arquitectónica para incorporar una alcoba ritual (cuarto C); lo cual sugiere que no todas las familias extensas estuvieron viviendo en las terrazas de la ladera con acceso a recursos para auspiciar reuniones festivas (y realizar actividades asociadas a la administración).

En Cerro Mejía, los trabajadores construían sus casas dependiendo de la configuración de su familia. En general, estas consistían en espacios de cocina cerrados y patios abiertos. Por otro lado, los miembros respetados de la comunidad, quizá uno por cada barrio, fueron como supervisores de mano de obra y deben haber tenido otras responsabilidades administrativas. Estos individuos tenían espacios especiales para encontrarse con jefes de otras familias, y este tipo de vivienda debió presentar los ambientes para preparar comida para más personas fuera del grupo familiar. Los restos de animales encontrados indican que hubo un acceso diferenciado a los alimentos que fueron preparados durante estas celebraciones, siendo estas las comidas a base de camélidos (cuadro 1). Es importante notar que la unidad 4 exhibió remodelaciones sustanciales, por lo que se podría sugerir que este rol administrativo fue obtenido más que heredado.

Cuadro 1 - Cantidad de fauna ósea por residencia

\begin{tabular}{|c|c|c|c|}
\hline Residencia & $\begin{array}{c}\text { Ubicación de } \\
\text { residencia }\end{array}$ & $\begin{array}{c}\text { Cantidad de fauna } \\
\text { ósea (g) }\end{array}$ & $\begin{array}{c}\text { Área de } \\
\text { residencia }\end{array}$ \\
\hline unidad 3 & Ladera aterrazada & 696,9 & $33 \mathrm{~m}^{2}$ \\
\hline unidad 5 & Ladera aterrazada & 299,2 & $11.6 \mathrm{~m}^{2}$ \\
\hline unidad 4 & Ladera aterrazada & 1448,4 & $54 \mathrm{~m}^{2}$ \\
\hline unidad 118 norte & Cumbre del cerro & 576 & $127 \mathrm{~m}^{2}$ \\
\hline unidad 118 sur & Cumbre del cerro & 1416,1 & $95 \mathrm{~m}^{2}$ \\
\hline unidad 145 & Cumbre del cerro & 4063 & $115 \mathrm{~m}^{2}$ \\
\hline
\end{tabular}

* Incluye el área de la residencia que fue excavada hasta la superficie del piso más alto y no incluye ninguna área que permanezca sin excavar

Las estructuras en la cima de Cerro Mejía muestran una gran variedad de tamaños y formas. La cima del sitio parece haber sido organizada alrededor de un espacio central abierto que no está delimitado por muros, pero tiene dos plataformas en el extremo este y dos pequeñas plataformas hacia el noroeste. Las dos únicas estructuras que exhiben una construcción con piedras trabajadas y se asemejan a un grupo-patio wari, están localizadas a cada lado de la plataforma de este 


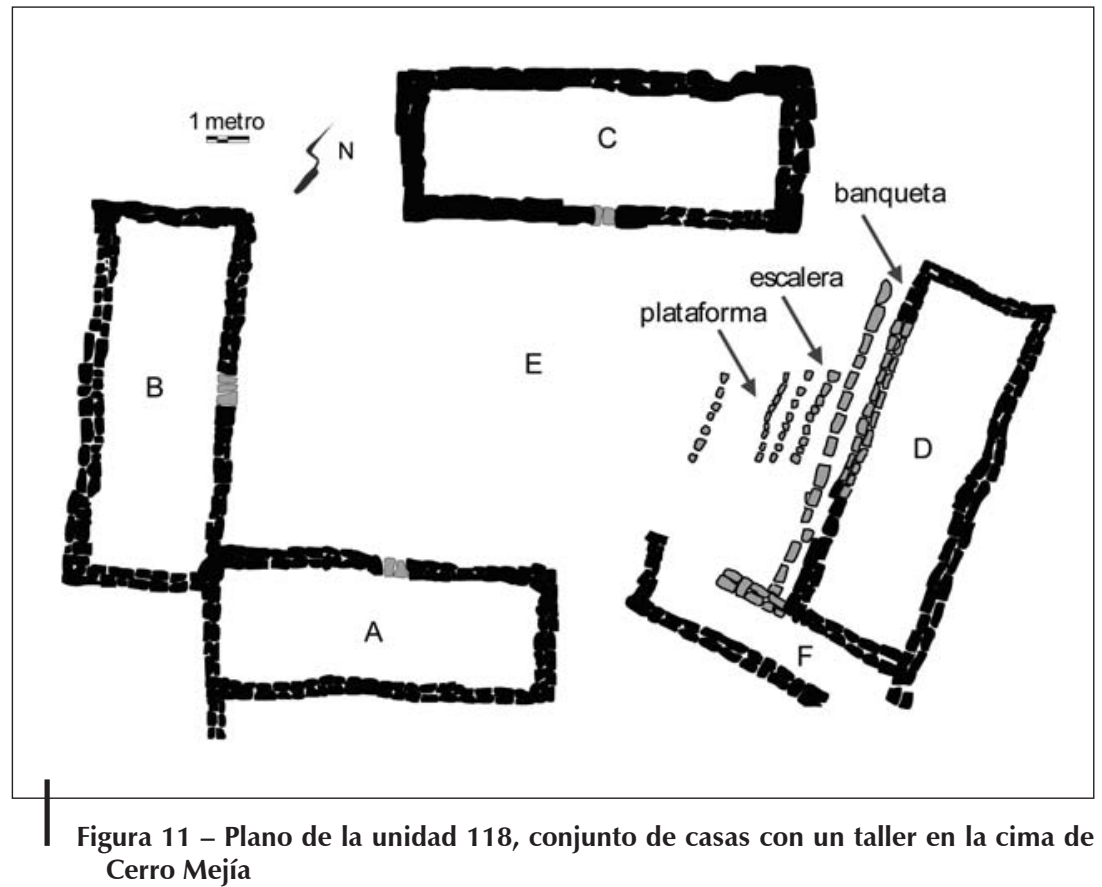

complejo. La más pequeña de estas dos estructuras fue seleccionada para ser excavada, así como una estructura que no exhibe la forma de un grupo-patio wari correspondiente a la unidad 118.

La unidad 118 fue un grupo residencial de gran tamaño compuesto por dos viviendas. Estas estructuras tuvieron un muro en común y no existía un acceso interno entre ambas viviendas (fig. 11). Cada vivienda mostró características similares, lo que sugiere que albergaron a familias extensas. La unidad 118 también presentó rasgos y espacios especializados que indican la presencia de un gran taller de algún tipo, aunque el producto de este trabajo no pudo ser determinado. Pero esta actividad requirió un gran número de batanes, pulidores manuales y muchas lascas que tenían formas para ser utilizadas como si fueran a pelar la corteza de una pequeña rama de árbol (cuarto C). Este grupo parece haber integrado medios de consumo similares a los de la unidad 4, situada alrededor de una gran roca ubicada en un patio exterior y de recinto cerrado y relativamente limpio con una pared posterior redondeada (cuarto $\mathrm{H}$ ), quizás utilizada para hacer observaciones rituales del paisaje. Por otro lado, la ausencia de desechos de producción en el cuarto $\mathrm{H}$, constituye una gran diferencia con las otras áreas de la estructura que contenía desechos de actividad dispersos (Nash, 2002).

El tamaño, elaboración y ubicación de este grupo de viviendas sugiere que algunos artesanos debieron haber gozado de un estatus elevado y el conjunto de herramientas asociadas avala esta interpretación (Nash, 2002). Si analizamos las unidades de viviendas separadas del conjunto, se puede sugerir que las unidades 
de producción tuvieron un líder propio, ya que una de las subresidencias (representada por los recintos F, G y H) comparte características con la unidad 4. Las dos tienen un espacio de encuentro que se halló limpio y donde no se realizaron actividades productivas (recinto $\mathrm{H}$ ). Además, los restos de fogones asociados a las zonas de cocina son similares en tamaño. Debido a las intensas actividades productivas, a la densidad de herramientas y basura presentes en este recinto, los patrones de actividades se hacen más difíciles de determinar.

La excavación en la unidad 145, la más pequeña de las dos residencias de grupopatio wari en el sitio, reveló aspectos mucho más importantes sobre los niveles intermedios de la actividad sociopolítica de la jerarquía administrativa wari. La estructura se asemeja vagamente a la organización espacial wari y representa esfuerzos de emulación de un administrador regional foráneo interesado en participar en esta sociedad.

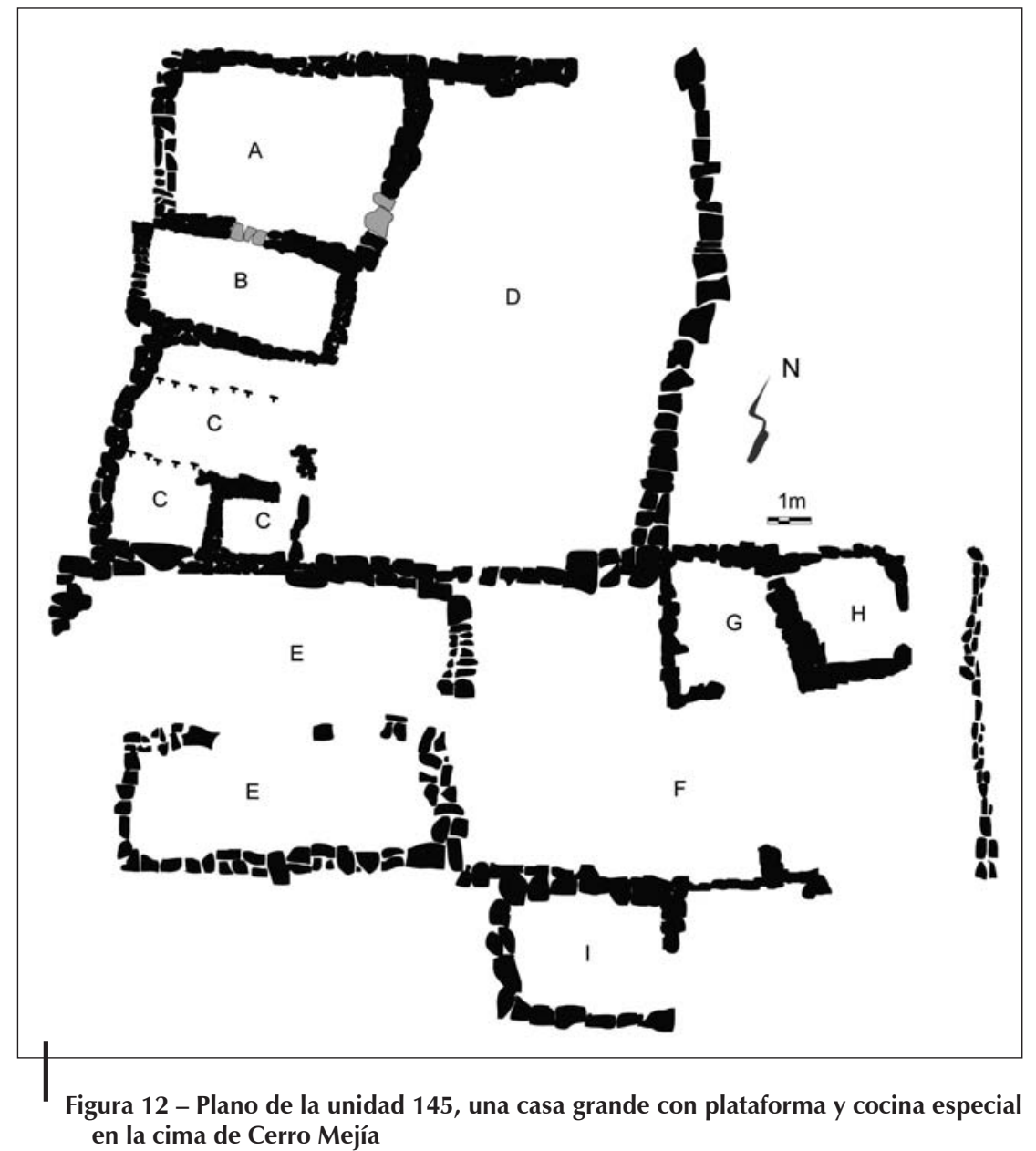


Los recintos rectangulares cerrados ubicados al sur y oeste del patio central (fig. 12), presentan características de viviendas típicas pero se encontraron increíblemente limpias, en comparación con los desechos domésticos que presentan las otras estructuras residenciales. El recinto A tiene un hoyo de almacenaje localizado en una esquina. Ambos recintos A y B tienen áreas que no presentan artefactos, y en algunos casos, el tamaño y las formas de estos hoyos sugieren que partes del piso estaban cubiertas de vasijas de almacenaje.

El recinto $C$ es un recinto rectangular hacia el lado norte, similar en forma a los recintos $\mathrm{A}$ y $\mathrm{B}$, pero es un contexto especializado para la preparación intensificada de alimentos y posiblemente chicha. Contenía siete fogones de dos tipos, numerosos restos de vasijas de cocina y almacenaje, y una gran cantidad de huesos de camélido carbonizados. Al este de la puerta había cuatro fogones de piedra alineados de forma más o menos circular, los cuales han sido interpretados como hallazgos diseñados para la ubicación de jarras, las que presumiblemente sirvieron para hervir la chicha. Estos son los únicos fogones que presentan madera carbonizada y sus formas se asemejan a los fogones asociados a la producción de chicha hallada en Cerro Baúl (Moseley et al., 2005). Los tres fogones restantes no tienen estructura alguna y estuvieron asociados con grandes cantidades de huesos de camélidos. Aún así, este ambiente tenía una mínima cantidad de desechos de producción que sugiere que la mayoría de veces la preparación preliminar de comidas ocurría en otro lugar. Así, la cocina ubicada en la unidad 145 es más grande de lo que probablemente se requería para la preparación de alimentos para la familia inmediata del líder. Esta tuvo dos zonas, una para el asado o cocina generalizada y la otra posiblemente utilizada para la producción de chicha.

El recinto D y el patio central proporcionan un espacio para realizar audiencias con los subordinados. Este recinto está ubicado hacia el este y es de forma rectangular, presenta la superficie del piso pavimentado con piedras y está más elevado en relación a los otros recintos y patio. Un hoyo de almacenaje en una esquina aún contenía fragmentos de piedras de sodalita y crisocola. Este recinto no tiene una apertura normal pues su puerta alcanza más de 2 metros de ancho mirando hacia el patio. A un escalón por debajo de la superficie del recinto se encuentra una banqueta y tres escalones que descienden a una plataforma ancha y elevada que se halla sobre el piso del patio central. Esta construcción proporciona un espacio alineado, en el cual la gente podía reunirse y posicionarse uno al lado del otro reflejando un orden social. Es así que de manera clara, esta estructura residencial fue diseñada para albergar interacciones sociopolíticas, preparar y proveer de agasajos a los visitantes, subordinados y quizás a grandes grupos que se reunieron en el patio central adyacente.

Por otro lado, en el centro del sitio hay cuatro plataformas, dos están localizadas hacia el este y las otras dos localizadas al noreste de una plaza larga y abierta que se encuentra en el medio (75 x 65 metros). El sitio ceremonial pudo haber sido un lugar donde la comunidad entera podía reunirse. Se sugiere que hasta cuatro líderes o grupos de líderes pudieron haber presidido eventos desde la parte 
superior de la plataforma. La arquitectura de la cima fue organizada alrededor de este complejo de la plaza. La primacía de las dos residencias formales «grupopatio wari», así como la de sus miembros, queda demostrada por su ubicación en ambos lados de este importante lugar público.

La estructura más grande en la cima de Cerro Mejía, la unidad 136, fue evaluada por áreas para observar si su componente arquitectónico grupo-patio wari contenía características similares a la de la unidad 145. El área correspondiente al recinto $\mathrm{D}$ en la unidad 145 parece haber sido utilizada de forma diferente debido a que una plataforma se extiende a lo largo del lado este de la gran plaza, en vez de entre los recintos de una configuración grupo-patio wari. De esta manera, las instalaciones de la unidad 136 pudieron haber albergado cuatro veces más personas que la unidad 145. Los rasgos asociados dentro de otros recintos rectangulares fueron idénticos a pesar de que sus posiciones alrededor del patio eran diferentes. Hubo un área de preparación intensiva de comida en una parte del grupo-patio de esta estructura. Futuras investigaciones en esta estructura pueden dar una mejor idea de los recursos administrados en esta región en el nivel terciario de esta política jerárquica.

\section{DISCUSIÓN}

La evidencia de Cerro Mejía demuestra que las actividades alrededor de la organización de festines relacionadas a la administración ocurrieron en dos escalas diferentes. Los alimentos excepcionales y la escasa importancia en la distribución de obsequios (representados por la amplia distribución de obsidiana) fueron significativos. Las estructuras residenciales fueron los lugares donde se llevaron a cabo interacciones que mantuvieron las relaciones asimétricas entre los administradores y sus subordinados, exhibiendo características de lo que Dietler (2001) denominó una festividad «patrón-servidor».

La población permanente estuvo administrada a través de contactos e intercambios con los administradores de menor nivel. La gente que tenía estos roles al parecer asumía el manejo de diez a quince unidades familiares. Probablemente, solo había uno de estos administradores en cada barrio ubicado en las laderas de Cerro Mejía. De esta manera, la unidad 145 representa un espacio que pudo albergar la reunión de cuatro a seis de estos individuos, aunque también pudo haber acomodado a otros subordinados. Los jefes de cada barrio fueron invitados a las fiestas por uno de los administradores en sus residencias de grupo-patio wari. En este ambiente los administradores debieron haber ofrecido regalos a los jefes de barrio que los legitimara de su posición y los exaltara por sobre los vecinos de barrio. En estos contextos, los jefes de barrio también recibieron otros recursos. Las evidencias sugieren que se repartían porciones de carne de camélido (Moseley et al., 2005), utilizada para agasajar a los grupos familiares bajo su mando (jefes de barrio), con la finalidad de recolectar y organizar los grupos de trabajo de acuerdo a la necesidad del mantenimiento de la producción agrícola. Por otro lado, los 
recursos para alimentar a los trabajadores durante su contribución en el trabajo de la mit'a pudieron haber provenido directamente de los almacenes estatales en lugar de haber sido canalizados a través de las unidades domésticas de los administradores de menor rango. Debido a que en las estructuras residenciales solo se encontraron pequeños cuartos de almacenamiento, estos debieron de haber existido en algún otro lugar de Cerro Mejía. Se sugiere que probablemente los almacenes se hallaban en una zona aún no excavada de la unidad 136, o en algún otro ambiente especial.

Los inkas tuvieron una institución especializada que fue el aqllawasi, formado por personal que se encargó de la preparación de chicha y las comidas para los festines importantes, respaldando a la administración imperial. En cambio, la elite wari utilizó diversos tipos de mano de obra para llevar a cabo estas festividades que respaldaban los agasajos relacionadas a la administración. Las áreas que presentan evidencias de una intensa preparación de comidas en las residencias administrativas pudieron haber sido utilizadas para preparar comidas especiales. Es posible que las mujeres asociadas con las unidades domésticas fueran las encargadas de preparar los festines de los importantes eventos políticos y económicos. El mismo grupo pudo haber preparado comida para los trabajadores durante los proyectos de trabajo, pero es posible que toda la comunidad contribuyera en estas tareas. Teóricamente, cada unidad familiar estaba en capacidad de proporcionar una comida en el campo (con el objetivo de plantar y cosechar anualmente) para un grupo más grande que los miembros de su unidad. Se sugiere que estas «fiestas de trabajo» (Dietler \& Herbich, 2001) pudieron haber variado diariamente de escala ya que atraían fuerza de trabajo adicional y fuera del grupo familiar. Los administradores del nivel más bajo pudieron haber adquirido su posición a través de la habilidad de su familia para atraer y movilizar mano de obra de esa forma. Las actividades llevadas a cabo por los administradores de los niveles bajos y para beneficio del Estado de cierta manera fueron una elaboración de prácticas que a su vez contribuyeron a la economía familiar. A pesar de que no hay evidencia de producción de chicha fuera de las estructuras determinadas como grupo-patio wari, es posible que en Moquegua la producción de chicha fuera restringida a los administradores de mediano a alto rango.

La interacción sociopolítica de pequeños grupos fue practicada en las viviendas de los líderes de ambos niveles. Las unidades 145 y 136 fueron específicamente diseñadas en función de la especialización de sus ocupantes. Estos espacios fueron creados para proveer el espacio requerido para llevar a cabo la administración y contó con los medios para almacenary producir bienes necesarios que acompañarán esta especialización. En contraste, la unidad 4 se fue acrecentando a través del tiempo. La fase de construcción más temprana asemeja a la típica casa de una familia extensa que tiene dos subunidades, la cual fue posteriormente modificada para incorporar el ambiente y el espacio necesario para un administrador de medio tiempo.

Es así que patrones importantes emergen si se hacen comparaciones entre los registros arqueológicos de las estructuras que se han descrito. El espacio es 
importante para la administración social. Un líder debe contar con un ambiente lo suficientemente grande para albergar a toda la gente bajo su mando. Este espacio pudo estar dentro de la residencia del líder, pero las relaciones de poder también se establecieron a través de las actividades realizadas en grandes espacios públicos (Nash \& Williams, 2005). El intercambio de alimentos por trabajo puede ocurrir en cualquier ambiente, pero se realiza sobre las relaciones preexistentes establecidas y mantenidas en espacios designados para legitimar el orden social. Múltiples ambientes públicos, residenciales y religiosos pueden reforzar las relaciones de poder y varias estrategias fueron utilizadas para mantener el control sobre los recursos (D'Altroy et al., 2000; Nash \& Williams, 2005). Las estructuras residenciales fueron una parte importante en este proceso de la sociedad wari. Estas casas no incorporaban de manera casual las actividades administrativas dentro de la esfera residencial, sino que fueron especialmente diseñadas o reestructuradas para albergar estas actividades y facilitar este tipo de acción productiva. En cualquier sociedad compleja, la administración es una ocupación especializada que está asociada a un conjunto de conocimientos particulares. Estos especialistas pudieron haber sido a medio o a tiempo completo, y tuvieron beneficios económicos. Así, estos especialistas estuvieron representados en el registro arqueológico por un conjunto de materiales y desechos provenientes de festines.

En los Andes, las fiestas fueron un componente importante de la administración residencial. Un líder debía tener acceso a los medios y al personal para preparar y llevar a cabo un festín. En base a las excavaciones realizadas se sugiere que, en comparación de sus vecinos, la unidad 4 tuvo un mayor acceso a recursos y pudo albergar al menos diez invitados en su sala especial ubicada en la entrada. Además, la presencia de un espacio más grande para cocinar permitía a más de una mujer atender el fuego, y una gran cantidad de desechos animales sugieren la preparación de comidas especiales. Por ejemplo, las casas ubicadas en las pendientes aterrazadas del sitio solo muestran una fracción de los restos de camélidos presentes en la unidad 4 (ver cuadro 1). Es interesante llamar la atención sobre la presencia de comidas especiales en la unidad 145, que incluyó chicha, pero la unidad 4 no muestra dos zonas de preparación. ¿Fue la producción y distribución de chicha controlada o limitada por la sociedad wari?

Arqueológicamente solo los espacios específicamente diseñados para facilitar la administración como las unidades 145 y 136 fueron fácilmente identificados. En esta investigación, los restos de varios contextos fueron comparados, no obstante se reconocieron interacciones políticas en zonas residenciales a través de un cuidadoso análisis del uso del espacio. Acá he enfatizado la clara organización espacial de las estructuras residenciales, pero aún faltan muchos aspectos por investigarse. En la actualidad, la administración puede ser entendida como la actividad que preside la reunión de gente con miembros que van más allá de la unidad doméstica. Estas actividades pudieron haber requerido de acceso a recursos para proveer de comidas especiales (por ejemplo, más carne de lo normal), y que en algunos casos pudo haber incluido chicha. Al respecto, existen muchos otros 
aspectos de la administración y de las actividades relacionadas a este, que pueden ser investigadas a través de mayores investigaciones arqueológicas.

Al momento, existen mayores viviendas excavadas en Cerro Mejía pero se requiere de mayor tiempo para analizar los datos a detalle. Adicionalmente, se cree haber encontrado otras comunidades del Horizonte medio a lo largo del canal wari que también atraviesa Cerro Mejía. En un futuro cercano, estos sitios serán investigados y los datos contribuirán a evaluar este modelo propuesto, debido a que pequeñas comunidades similares a las de Cerro Mejía debieron haber tenido un administrador de baja escala con las facilidades y recursos similares a los de las unidades 4 y 5 . Asimismo, con un conjunto de datos más completos será posible observar los objetos que fueron controlados por el Estado wari, como la obsidiana, que fue distribuida a lo largo de la colonia.

Aquí se ha presentado un modelo que delinea la administración política Wari dentro de los centros provinciales, basada en el uso del espacio residencial de un centro terciario como Cerro Mejía. Este centro vincula a los trabajadores, los administradores de bajo nivel y al personal del Estado de nivel medio. Estos oficiales estuvieron actuando bajo la dirección de los gobernadores provinciales wari situados en Cerro Baúl, emulando fuertemente un comportamiento administrativo provincial (Nash \& Williams, 2005). Las investigaciones realizadas en Cerro Mejía se enfocaron en las viviendas y el llamar la atención en el uso del espacio constituye un paso más allá para entender la administración y las relaciones de poder que contribuyeron a la expansión y al sostenimiento del Estado wari. Hay aún otros aspectos a explorar pero al examinar los contextos y los artefactos juntos podemos tener un mejor entendimiento del pasado andino.

\section{Agradecimientos}

Los fondos para realizar la investigación en Cerro Mejía fueron provistos por la Fundación Nacional de Ciencia de EE.UU. (BSC-9907167), el Centro para Estudios Latinoamericanos de la Universidad de Florida y la Asociación Contisuyo. El trabajo de campo fue ejecutado con el permiso del Instituto Nacional de Cultura, Lima (Resolución n. 988-1999). Además, mi agradecimiento es para los colegas y estudiantes quienes con su ayuda hicieron posible el Proyecto de Cerro Mejía, como Susan deFrance, Ana Miranda, Kenneth Sims, Shanna Schoefield, Adán Umire y especialmente a Ryan Williams; así como al preparado equipo de campo local que he heredado de todos los arqueólogos que han trabajado en Moquegua a través de los años. Le agradezco a Betty de Olazabal por su apoyo y su amistad durante las etapas de investigación en Perú; así también agradezco al Museo Contisuyo. También quisiera agradecer a muchas personas que proporcionaron comentarios a este artículo en versiones anteriores, como Chap Kusimba y Michael Moseley, los evaluadores anónimos, Vanessa Ponce de León y Anne-Marie Brougère, y los estudiantes que prepararon algunas de las figuras, como Megan Allen, Rachal Maass y Caleb Macdonald. Un agradecimiento especial a Sofía Chacaltana quien tradujo el trabajo al español, así como a Emilie Utiguard, Mark Golitko y Laure Dussubieux quienes tradujeron el resumen al francés. Cualquier error u omisión es por supuesto mío. 


\section{Referencias citadas}

ANDERS, M., 1991 - Structure and Function at the Planned Site of Azángaro: Cautionary Notes for the Model of Huari as Centralized Secular State. In: Huari Administrative Structure: Prehistoric Monumental Architecture (W. Isbell \& G. McEwan, eds.): 165199; Washington, D. C. :Dumbarton Oaks Research Library and Collection.

ALDENDERFER, M. (ed.), 1993 - Domestic architecture in south-central andean prehistory, 178 pp.; lowa City: University of lowa Press.

ALDENDERFER, M., 1998 - Montane foragers: Asana and the south-central andean Archaic, 327 pp.; lowa City: University of lowa Press.

ARDENER, S. (ed.), 1981 - Women and space: Ground rules and social maps, 239 pp.; London: Croom Helm.

BACHELARD, G., 1969 - The poetics of space, 241 pp.; Boston: Beacon Press.

BADIAN, E., 1968 - Roman imperialism in the Late Republic, 117 pp.; Oxford: Blackwell Press. Second Edition.

BAUER, B., 1996 - The legitimization of the Inka State in myth and ritual. American Anthropologist, 98 (2): 327-337.

BAWDEN, G., 1990 - Domestic space and social structure in the Pre-Columbian Northern Peru. In: Domestic architecture and the use of space (S. Kent, ed.): 153-171; New York: Cambridge University Press.

BETANZOS, J. de, 1987 [1557] - Narrative of the Incas, 326 pp.; Austin: University of Texas Press.

BOLIN, I., 1998 - Rituals of respect: The secret of survival in the high Peruvian Andes, 289 pp.; Austin: University of Texas Press.

BOURDIEU, P., 1977 - Outline of a theory of practice, 248 pp.; Cambridge: Cambridge University Press.

BOURDIEU, P., 1979 - The Kabyle House of the world reversed. In: Algeria 1960 (P. Bourdieu, ed.): 133-153; Cambridge: Cambridge University Press.

BREWSTER-WRAY, C., 1989 - Huari administration: a view from the capital. In: The Nature of Wari ( R. Czwarno, F. Meddens \& N. Morgan, eds.): 23-33; Oxford: BAR International Series 525.

CARDONA, A., 2002 - Arqueología de Arequipa de sus Albores a los Incas, 178 pp.; Arequipa: CIARQ.

CHACALTANA, S. \& NASH, D., 2009 - Las ofrendas como tradición de origen prehispánico: El caso de Cerro Baúl, valle alto de Moquegua. In: Las Actas del Simposio Internacional sobre Arqueología del Área Centro Sur Andina (A. Belan Franco, M. Ziołkowski \& J. Jennings, eds): 693; Arequipa: Universidad Católica de Santa María.

COOK, A., 2001 - Huari D-Shaped structures, sacrificial offerings and divine rulership. In: Ritual sacrifice in ancient Peru (E. Benson \& A. Cook, eds.): 137-163; Austin: University of Texas Press.

COOK, A. \& GLOWACKI, M., 2003 - Pots, politics, and power: Huari ceramic assemblages and imperial administration. In: The Archaeology and Politics of Food and Feasting in Early States and Empires (T. Bray, ed.): 173-202; New York: Kluwer Academic.

COSTIN, C., 1998 - Housewives, chosen women, skilled men: Cloth production and social identity in the Late Prehispanic Andes. In: Craft and social identity (C. Costin \& R. Wright, eds.): 123-141; Washington, D. C.: Archaeological Papers of the American Anthropological Association No. 8, American Anthropological Association. 
El establecimiento de relaciones de poder a través del uso del espacio residencial en la provincia Wari

D'ALTROY, T., 1987 - Transitions in power: Centralization of Wanka political organization under Inka rule. Ethnohistory, 34: 78-102.

D'ALTROY, T., 2002 - The Inkas, 391 pp.; Oxford: Blackwell Press.

D'ALTROY, T. \& HASTORF, C., 2001 - Empire and Domestic Economy, 390 pp.; New York: Kluwer, Plenum Academic.

D'AlTROY, T., LORANDI, A. M., WILliAMS, V., CALDERARI, M., HASTORF, C., DEMARRAIS, E. \& HAGSTRUM, M., 2000 - Inka rule in the northern Calchaqui valley, Argentina. Journal of Field Archaeology, 27 (1): 1-26.

DIETLER, M., 2001 - Theorizing the feast: Rituals of consumption, commensal politics, and power in African contexts. In: Feasts: Archaeological and ethnographic perspectives on food, politics, and power (M. Dietler \& B. Hayden, eds.): 65-114; Washington D. C.: Smithsonian Institution Press.

DIETLER, M. \& HERBICH, I., 2001 - Feasts and labor mobilization: Dissecting a fundamental economic practice. In: Feasts: Archaeological and ethnographic perspectives on food, politics, and power (M. Dietler \& B. Hayden, eds.): 240-264; Washington D. C.: Smithsonian Institution Press.

DOBRES, M., 2000 - Technology and social agency: Outlining a practice framework for archaeology, 300 pp.; Oxford: Blackwell Press.

DONLEY-REID, L., 1990 - A structuring structure: The Swahili House. In: Domestic architecture and the use of space (S. Kent, ed.): 114-126; New York: Cambridge University Press.

DOUGLAS, M., 1973 - Natural symbols: Explorations in cosmology, 218 pp.; New York: Penguin Books.

EVANS, S. T., 2004 - Aztec palaces and other elite residential architecture. In: Palaces of the Ancient New World (S. T. Evans \& J. Pillsbury, eds.): 7-58; Washigton D. C.: Dumbarton Oaks.

GERO, J., 2001 - Field knots and ceramic beaus: Interpreting gender in the Peruvian Early Intermediate Period. In: Gender in Pre-Hispanic America (C. Klein, ed.): 15-55; Washigton D. C.: Dumbarton Oaks.

GERO, J. \& SCATTOLIN, C., 2002 - Beyond complimentarity and hierarchy: New dimensions for archaeological gender relations. In: In pursuit of gender: Worldwide archaeological approaches (S. M. Nelson \& M. Rosen-Ayalon, eds.): 155-172; New York: Alta Mira Press.

GIDDENS, A., 1979 - Central problems in social theory: Action, structure and contradiction in social analysis, 294 pp.; London: Allen and Urwin.

GIDDENS, A., 1981 - A contemporary critique of historical materialism. Vol. 1: Power, property and the state, 108 pp.; London: Macmillan.

GLOWACKI, M., 2002 - The Huaro Archaeological Site Complex: Rethinking the Huari Occupation of Cuzco. In: Andean Archaeology I: Variations in Sociopolitical Organization (W. Isbell \& H. Silverman, eds.): 267-286; New York: Kluwer Academic, Plenum Publishers.

GOODY, J., 1972 - The evolution of the family. In: Household and family in past time (P. Laslett \& R. Wall, ed.): 103-124; Cambridge: Cambridge University Press.

GOSE, P., 1996 - Oracles, divine kingship, and political representation in the Inka State. Ethnohistory, 43 (1): 1-32.

HALL, E. T., 1981 - The silent language, 217 pp.; New York: Anchor Books.

ISBELL, W. H., 1978 - The rural foundation for urbanism: Economic and stylistic interaction between rural and urban communities in eighth-century Peru, 188 pp.; Urbana: University of Illinois Press. 
ISBELL, W. H., 1989 - Honcopampa: Was it a Huari administrative centre? In: The nature of Wari: A reappraisal of the Middle Horizon Period in Peru (R. M. Czwarno, F. M. Meddens \& A. Morgan, eds.): 98-115; Oxford: BAR International Series 525; British Archaeological Series.

ISBELL, W. H., 1991 - Huari administration and the orthogonal cellular horizon. In: Huari administrative structure: Prehistoric monumental architecture and state government (W. Isbell \& G. McEwan, eds.): 293-316; Washignton, D. C.: Dumbarton Oaks.

ISBELL, W. H., 2004 - Palaces and Politics in the Andean Middle Horizon. In: Palaces of the Ancient New World (S. Evans \& J. Pillsbury, ed.): 7-58; Washington, D. C.:Dumbarton Oaks Research Library and Collection.

ISBELL, W. H., 2007 - A Community of Potters, or Multicrafting Wives of Polygynous Lords? In: Craft Production in Complex Societies: Multicraft and Producer Perspectives (I. Shimada, ed.): 68-96; Salt Lake City: The University of Utah Press.

ISBELL, W. H. \& GROLEAU, A., 2010 - The Wari Brewer Woman: Feasting, Gender, Offerings, and Memory. In: Inside Ancient Kitchens: New Directions in the Study of Daily Meals and Feasts (E. Klarich, ed.): 191-220; Boulder: University Press of Colorado.

ISBELL, W. H. \& McEWAN, G., 1991 - A history of Huari studies and introduction to current interpretations. In: Huari administrative structure: Prehistoric monumental architecture and state government (W. Isbell \& G. McEwan, eds.): 1-18; Washington D. C.: Dumbarton Oaks.

ISBELL, W. H., BREWSTER-WRAY, C. \& SPICKARD, L., 1991 - Architecture and spatial organization at Huari. In: Huari Administrative Structure: Prehistoric Monumental Architecture and State Government (W. Isbell \& G. McEwan, eds.): 19-54; Washington D. C.: Dumbarton Oaks Research Library and Collection.

JULIEN, C., 1982 - Inca decimal administration in the Lake Titicaca Region. In: The Inca and Aztec States 1400-1800: Anthropology and history (G. Collier, R. Resaldo \& J. Wirth, eds.): 96-112; New York: Academic Press.

KENT, S. (ed.), 1990 - Domestic Architecture and the Use of Space, 192 pp.; New York: Cambridge University Press.

McEWAN , G., 1991 - Investigations at the Pikillacta Site: A Provincial Huari Center in the Valley of Cuzco. In: Huari administrative structure: Prehistoric monumental architecture and state government (W. Isbell \& G. McEwan, eds.): 93-120; Washington D. C.: Dumbarton Oaks.

McGAW, J. A., 1996 - Reconceiving Technology: Why Feminine Technologies Matter. In: Cender and archaeology (R. Wright, ed.): 111-142; Philadelphia: University of Pennsylvania Press.

MEYERSON, J., 1990 - Tambo: Life in an Andean village, 265 pp.; Austin: University of Texas Press.

MORRIS, C., 1982 - The infrastructure of Inka control in the Peruvian central highlands. In: The Inca and Aztec States 1400-1800: Anthropology and history (G. Collier, R. Resaldo \& J. Wirth, eds.): 153-171; New York: Academic Press.

MORRIS, C., 1995 - Symbols to power: Styles and media in the Inka State. In: Society, and person: Archaeological and ethnological perspectives Style (C. Carr \& J. Neitzel, eds.): 419-433; New York: Plenum Press.

MORRIS, C. \& THOMPSON, D. E., 1985 - Huánuco Pampa: An Inca City and its Hinterland, 181 pp.; London: Thames and Hudson.

MOSELEY, M. E., 2001 - The Inca and their ancestors: The archaeology of Peru, 288 pp.; London: Thames and Hudson. Revised Edition. 
El establecimiento de relaciones de poder a través del uso del espacio residencial en la provincia Wari

MOSELEY, M. E., FELDMAN, R., GOLDSTEIN, P. \& WATANABE, L., 1991 - Colonies and conquest: Tiahuanaco and Huari in Moquegua. In: Huari administrative structure: Prehistoric monumental architecture and state government (W. Isbell \& G. McEwan, eds.): 121-140; Washington, D. C.: Dumbarton Oaks. Washington.

MOSELEY, M. E., NASH, D. J., WILLIAMS, P. R., DEFRANCE, S. D., MIRANDA, A. \& RUALES, M., 2005 - Burning down the brewery: Establishing and evacuating an ancient imperial colony at Cerro Baúl, Peru. The Proceedings of the National Academy of Sciences, 102 (48): 17264-17271.

MURRA, J. V., 1980 - The economic organization of the Inka State. Journal of Archaeological Investigation, 208 pp.; Connecticut: JAI Press.

MURRA, J. V., 1982 - The mit'a obligations of ethnic groups to the Inka State. In: The Inca and Aztec States 1400-1800: Anthropology and history (G. Collier, R. Rosaldo, \& J. Wirth, eds.): 239-262; New York: Academic Press.

NASH, D. J., 2002 - The archaeology of space: Places of power in the Wari Empire, 385 pp.; Gainesville: Universidad de Florida. Tesis doctoral no publicada.

NASH, D. J., 2010 - Fine dining and fabulous atmosphere: Feasting facilities and political interaction in the Wari realm. In: Inside Ancient Kitchens: New Directions in the Study of Daily Meals and Feasting Events (E. Klarich, ed.): 83-110; Boulder: University of Colorado Press.

NASH, D. J., 2011 - Fiestas y la economía política Wari en Moquegua, Perú. Chungara, 43: 221-242.

NASH, D. J. \& BARRIONUEVO, R., 2009 - Informe-Proyecto Arqueológico Asentamientos en Cerro Mejía 2008 (ACME 1); Lima: Instituto Nacional de Cultura.

NASH, D. J. \& WILLIAMS, P. R., 2005 - Architecture and power: Relations on the WariTiwanaku frontier. In: The foundations of power in the Prehispanic Andes (K. Vaughn, C. Conlee \& D. Ogburn eds.): 151-174. Archaeological Papers of the American Anthropological Association n. ${ }^{\circ} 14$.

NASH, D. J. \& WILLIAMS, P., 2009 - Wari Provincial Organization on the Southern Periphery. In: The Foundations of Andean Civilization: Works in Honor of Michael Moseley (J. Marcus \& P. Williams, eds.): 253-272; Los Ángeles: Cotsen Institute of Archaeology, University of California.

NORBERG-SCHULZ, C., 1985 - The concept of dwelling: On the way to figurative architecture, 140 pp.; New York: Electa Press.

OHNUKI-TIERNEY, E., 1972 - Spatial concepts of the Ainu of the northwest coast southern Sakhalin. American Anthropologist, 74: 426-457.

OLIVER, P., 1990 - Dwellings: The house across the world. Second Edition, 256 pp.; Austin: University of Texas Press.

PADER, E. J., 1988 - Inside spatial relations. Architecture and Behavior, 4 (3): 251-267.

RAPOPORT, A., 1969 - House form and culture, 146 pp.; Englewood Cliffs: Prentice Hall.

RAPOPORT, A., 1990 - The meaning of the built environment, 253 pp.; Beverly Hills: Sage Publications.

ROSTWOROWSKI DE DIEZ CANSECO, M., 1999 - History of the Inca realm, 259 pp.; Cambridge: Cambridge University Press.

ROWE, J., 1946 - Inca culture at the time of the Spanish conquest. In: The Andean Civilizations Handbook of South American Indians, vol. 2 (J. H. Steward ed.): 183330; Washington, D. C.: Bureau of American Ethnology, Smithsonian Institution.

ROWE, J., 1982 - Inca policies and institutions relating to cultural unification of the empire. In: The Inca and Aztec States 1400-1800: Anthropology and history (G. Collier, R. Resaldo \& J. Wirth, eds.): 93-118; New York: Academic Press. 
SANTILLÁN, F. de, 1950 [1563] - Relación del origen, descendencia, política y gobierno de los Incas. In: Tres relaciones de antigüedades peruanas ( $M$. Jiménez de la Espada, eds.): ; Asunción de Paraguay: Editorial Guaranía.

SCHREIBER, K. J., 1992 - Wari imperialism in Middle Horizon Peru, 332 pp.; Ann Arbor: University of Michigan Press.

SCHREIBER, K. J., 2001 - The Wari Empire of the Middle Horizon Peru: The epistemological challenge of documenting an empire without documentary evidence. In: Empires: Perspectives from archaeology and history (S. E. Alcock, T. N. D'Altroy, K. Morrison \& C. Sinopoli, eds.): 70-92; Cambridge University Press.

SCHREIBER, K., 2005 - Sacred Landscapes and Imperial Ideologies: The Wari Empire in Sondondo, Peru. In: The Foundations of Power in the Prehispanic Andes (K. Vaugn, C. Conlee \& D. Ogburn, eds.): 131-150.

SCOTT, J., 1998 - Seeing Like a State: How Certain Schemes to Improve the Human Condition Have Failed, 464 pp.; New Haven: Yale University Press.

SINOPOLI, C., 1994 - The archaeology of empires. Annual Review of Anthropology, 23: 159-180.

SPICKARD, L., 1983 - The development of Huari administrative architecture. In: Investigations of the Andean Past (D. Sandweiss, ed.): 136-160; Ithaca: Cornell Latin American Studies Program.

STANISH, C., 1989 - Household archaeology. American Anthropologist, 91 (1): 7-24.

STANISH, C., 1992 - Ancient Andean political economy, 195 pp.; Austin: University of Texas Press.

STEVENSON, M. G., 1982 - Toward an understanding of site abandonment behavior: Evidence from historic mining camps in southwest Yukon. Journal of Anthropological Research, 1: 237-265.

TOOKER, E., 1978 - The league of the Iroquois: Its history, polities, and ritual. In: Northeast Handbook of North American Indians, Vol. 13 (B. Trigger, ed.): 418-441; Washington, D. C.: Smithsonian Institution.

TRINGHAM, R., 1991 - Households with faces: The challenge of gender in prehistoric architectural remains. In: Engendering Archaeology: Women and Prehistoric (J. Gero \& M. Conkey, eds.): 93-131; Oxford: Blackwell.

TUNG, T., 2007 - The village of Beringa at the periphery of the Wari Empire: A site overview and new radiocarbon dates. Andean Past, 8: 253-86.

WEISMANTEL, M., 1988 - Food, gender, and poverty in the Ecuadorian Andes, 234 pp.; Philadelphia: University of Pennsylvania Press.

WILLIAMS, P. R., 2001 - Cerro Baúl: A Wari center on the Tiwanaku frontier. Latin American Antiquity, 12 (1): 67-83.

WILLIAMS, P. R. \& NASH, D. J., 2002 - Imperial interaction in the Andes: Wari and Tiwanaku at Cerro Baúl. In: Andean Archaeology I (W. Isbell \& H. Silverman, eds.): 243-266; New York: Plenum.

ZUIDEMA, R. T., 1990 - Inca civilization in Cuzco, 101 pp.; Austin: University of Texas Press. 